
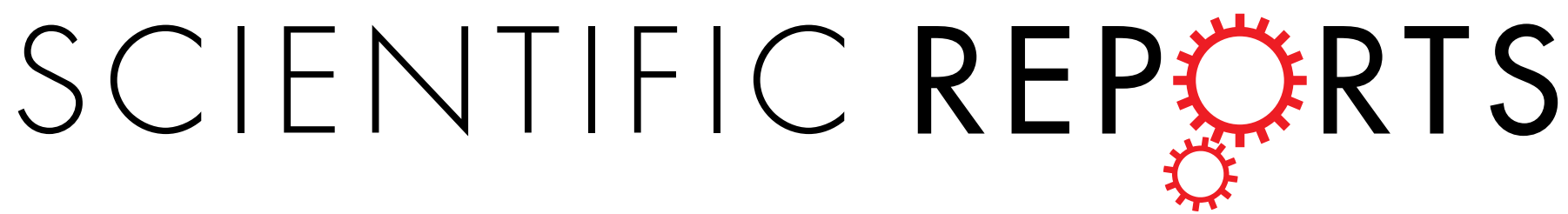

\title{
OPEN Tauroursodeoxycholic acid reduces ER stress by regulating of Akt- dependent cellular prion protein
}

Received: 01 June 2016

Accepted: 28 November 2016

Published: 22 December 2016
Yeo Min Yoon ${ }^{1, *}$, Jun Hee Lee ${ }^{2, *}$, Seung PilYun ${ }^{3, *}$, Yong-Seok Han ${ }^{1}$, Chul Won Yun ${ }^{1}$, Hyun Jik Lee ${ }^{4}$, Hyunjin Noh ${ }^{5}$, Sei-Jung Lee ${ }^{4}$, Ho Jae Han ${ }^{4} \&$ Sang Hun Lee ${ }^{1,6}$

Although mesenchymal stem cells (MSCs) are a promising cell source for regenerative medicine, ischemia-induced endoplasmic reticulum (ER) stress induces low MSC engraftment and limits their therapeutic efficacy. To overcome this, we investigated the protective effect of tauroursodeoxycholic acid (TUDCA), a bile acid, on ER stress in MSCs in vitro and in vivo. In ER stress conditions, TUDCA treatment of MSCs reduced the activation of ER stress-associated proteins, including GRP78, PERK, eIF2 $\alpha$, ATF4, IRE1 $\alpha$, JNK, p38, and CHOP. In particular, TUDCA inhibited the dissociation between GRP78 and PERK, resulting in reduced ER stress-mediated cell death. Next, to explore the ER stress protective mechanism induced by TUDCA treatment, TUDCA-mediated cellular prion protein ( $\left.\operatorname{Pr} P^{C}\right)$ activation was assessed. TUDCA treatment increased $\operatorname{PrP}^{C}$ expression, which was regulated by Akt phosphorylation. Manganese-dependent superoxide dismutase (MnSOD) expression also increased significantly in response to signaling through the TUDCA-Akt axis. In a murine hindlimb ischemia model, TUDCA-treated MSC transplantation augmented the blood perfusion ratio, vessel formation, and transplanted cell survival more than untreated MSC transplantation did. Augmented functional recovery following MSC transplantation was blocked by $\mathrm{PrP}^{\mathrm{C}}$ downregulation. This study is the first to demonstrate that TUDCA protects MSCs against ER stress via Akt-dependent PrPC and Akt-MnSOD pathway.

Mesenchymal stem cells (MSCs) are promising candidates for cell-based therapies in regenerative medicine owing to their self-renewal, multidirectional differentiation, and immunomodulation potential ${ }^{1}$. However, application of MSCs in cell therapy has shown low therapeutic efficacy resulting from various stress conditions, including oxidative stress, inflammation, and toxic environments cause by ischemia ${ }^{1,2}$. Under these pathophysiological conditions, oxidative stress induced the production of reactive oxidative species (ROS), resulting in prolonged endoplasmic reticulum (ER) stress ${ }^{3}$. The ER plays a pivotal role in cell survival and homeostatic regulation. Disruption of ER homeostasis results in the accumulation of unfolded proteins and apoptosis ${ }^{3,4}$.

Cellular prion protein $\left(\mathrm{PrP}^{\mathrm{C}}\right)$ is a glycoprotein. Conversion into its misfolded isoform proteinase resistant protein $\left(\mathrm{PrP}^{\mathrm{Sc}}\right)$ causes neurodegenerative disorders, also known as prion disease ${ }^{5,6}$. Although many efforts have been made to explore the physiological role of $\mathrm{PrP}^{\mathrm{C}}$, its function is still elusive and controversial. $\operatorname{PrP}^{\mathrm{C}}$ plays roles in neural precursor proliferation during developmental and adult mammalian neurogenesis ${ }^{7}$. In particular, $\mathrm{PrP}^{\mathrm{C}}$ enhances neurogenesis and angiogenesis through proteasome activity following ischemic brain injury ${ }^{8}$. Moreover, $\operatorname{PrP}^{\mathrm{C}}$ mediates cell adhesion via interaction with components of the extracellular matrix, such as laminin and vitronectin ${ }^{9}$. In hematopoietic stem cells (HSCs), $\mathrm{PrP}^{\mathrm{C}}$ is expressed on long-term HSCs and regulates their self-renewal ${ }^{10}$. Therefore, understanding how $\mathrm{PrP}^{\mathrm{C}}$ is linked to oxidative stress in ischemic conditions and what

\footnotetext{
${ }^{1}$ Medical Science Research Institute, Soonchunhyang University Seoul Hospital, Seoul, Republic of Korea. ${ }^{2}$ Department of Pharmacology and Toxicology, University of Alabama at Birmingham School of Medicine, Birmingham, AL 35294, USA. ${ }^{3}$ Neuroregeneration and Stem Cell Programs, Institute for Cell Engineering Department of Neurology, The Johns Hopkins University School of Medicine, Baltimore, USA. ${ }^{4}$ Department of Veterinary Physiology, College of Veterinary Medicine and Research Institute for Veterinary Science, and BK21 PLUS Creative Veterinary Research Center, Seoul National University, Seoul 151-741, Republic of Korea. ${ }^{5}$ Department of Internal Medicine, Hyonam Kidney Laboratory, Soonchunhyang University, Seoul, Republic of Korea. ${ }^{6}$ Departments of Biochemistry, Soonchunhyang University College of Medicine, Cheonan, 330-930, Republic of Korea. ${ }^{*}$ These authors contributed equally to this work. Correspondence and requests for materials should be addressed to H.J.H. (email: hjhan@snu.ac.kr) or S.H.L. (email: ykckss1114@nate.com)
} 
a

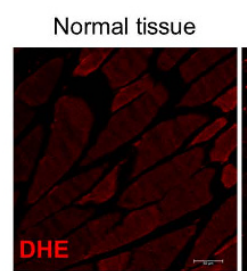

Ischemic tissue
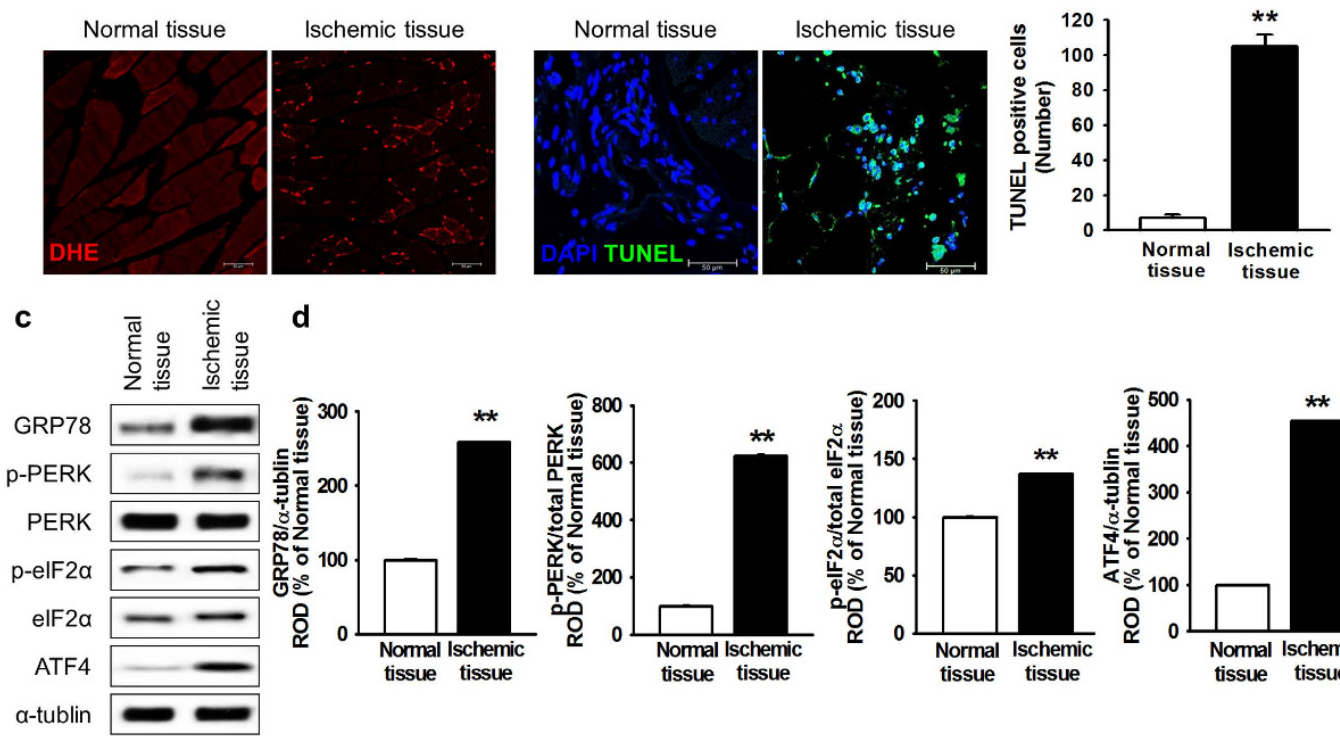

d

d
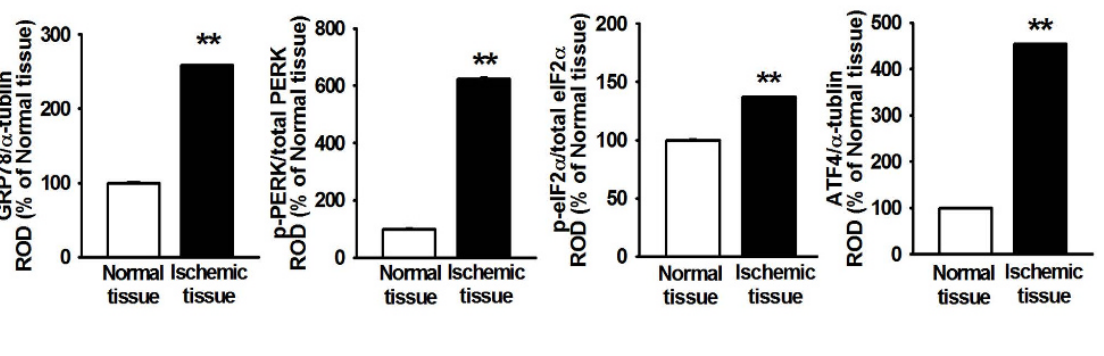

e
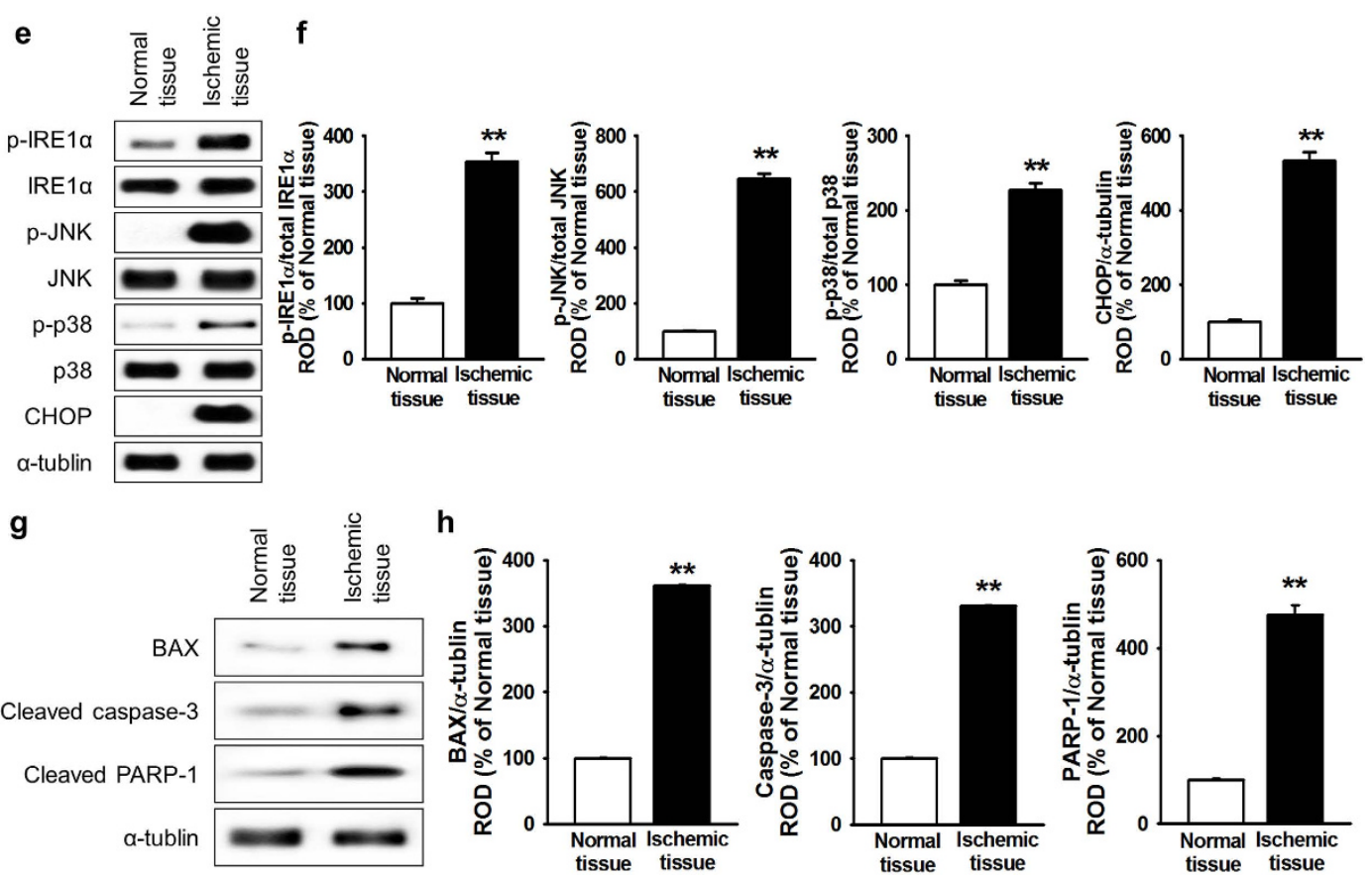

Figure 1. Ischemia-induced cell death via ROS-mediated ER stress. (a) Three days after the murine hindlimb ischemia operation, ROS levels in ischemic-injured tissues were assessed using DHE staining. (b) Three days after the murine hindlimb ischemia operation, apoptotic cells in ischemic-injured tissues were investigated using the TUNEL assay. The right panel represents the number of TUNEL-positive cells per high-power field. Values represent the mean \pm SEM. ${ }^{\star *} P<0.01$ vs. normal tissues. Scale bar $=50 \mu \mathrm{m}$. (c) Western blot analysis showing the expression of GRP78, p-PERK, PERK, p-eIF2 $\alpha$, eIF2 $\alpha$, and ATF4 in ischemic-injured tissues at postoperative day 3. (d) The expression levels of GRP78, p-PERK, p-eIF2 $\alpha$, and ATF4 were normalized to those of $\alpha$-tubulin, PERK, or eIF $2 \alpha$, respectively. Values represent the mean \pm SEM. ${ }^{\star *} P<0.01$ vs. normal tissues. (e) Western blot analysis of p-IRE1 $\alpha$, IRE1 $\alpha$, p-JNK, JNK, p-p38, p38, and CHOP expression in ischemicinjured tissues at postoperative day 3. (f) The expression levels of p-IRE1 $\alpha$, p-JNK, p-p38, and CHOP were normalized to those of IRE1 $\alpha$, JNK, p38, or $\alpha$-tubulin, respectively. Values represent the mean \pm SEM. ${ }^{* *} P<0.01$ vs. normal tissues. (g) Western blot analysis showing the expression of BAX, cleaved caspase- 3 , and cleaved PRAP-1 in ischemic-injured tissues at postoperative day 3. (h) The expression levels of BAX, cleaved caspase- 3 , and cleaved PRAP- 1 were normalized to that of $\alpha$-tubulin. Values represent the mean \pm SEM. ${ }^{*} P<0.01$ vs. normal tissues. Abbreviations: DHE, dihydroethidium; TUNEL, terminal deoxynucleotidyl transferase dUTP nick end labeling; GRP78, 78-kDa glucose-regulated protein; PERK, protein kinase R-like endoplasmic reticulum kinase; eIF2 $\alpha$, eukaryotic initiation factor 2-alpha; ATF4, activating transcription factor 4; IRE1 $\alpha$, inositol-requiring enzyme 1 alpha; JNK, c-Jun N-terminal kinase; CHOP, C/EBP homologous protein; BAX, B-cell lymphoma 2-associated X protein; PARP-1, poly(ADP ribose) polymerase- 1. 


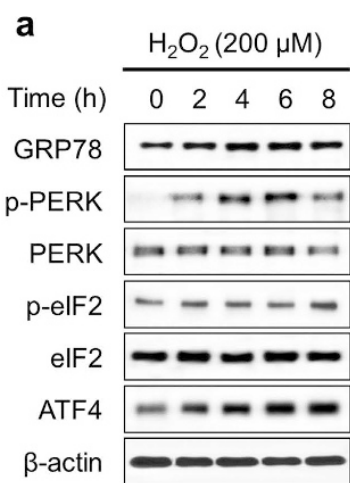

e

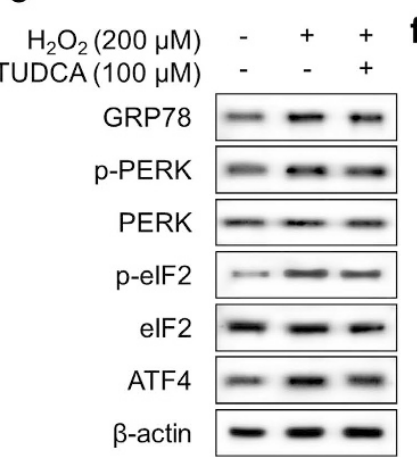

i

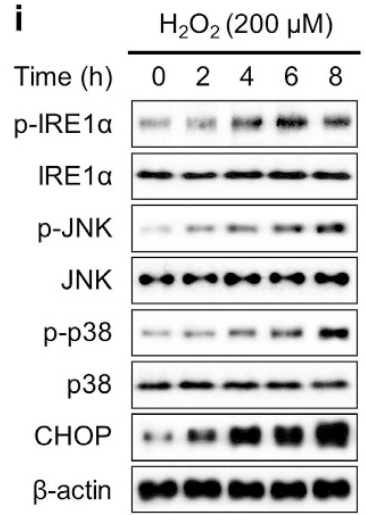

k

$\mathrm{H}_{2} \mathrm{O}_{2}(200 \mu \mathrm{M})$

TUDCA $(100 \mu \mathrm{M})$

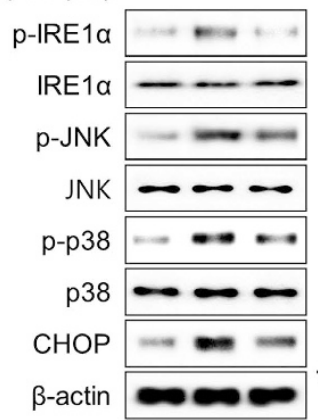

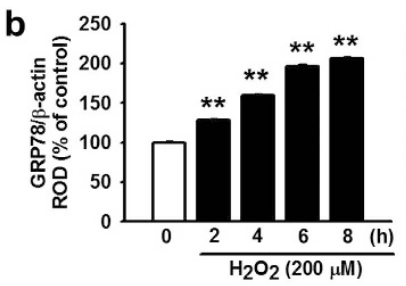
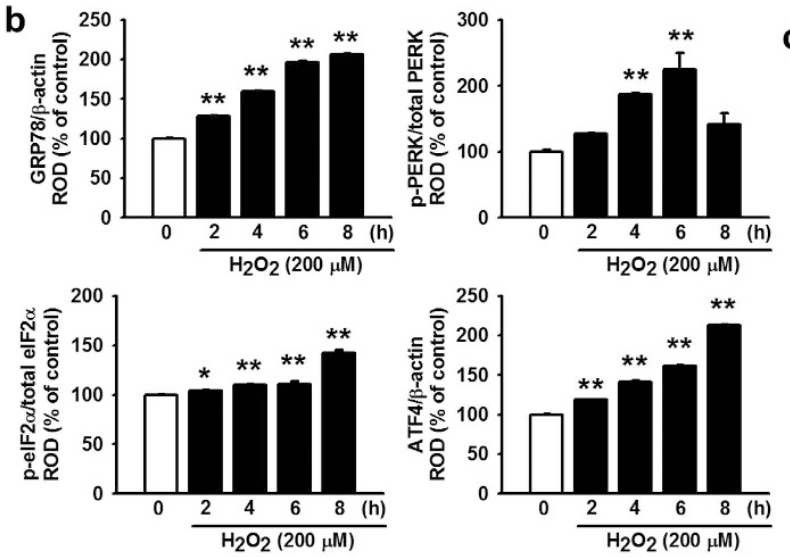

d
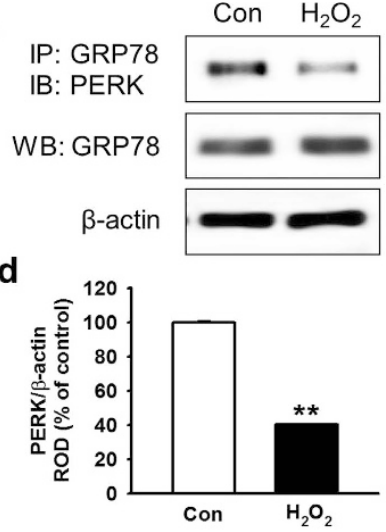
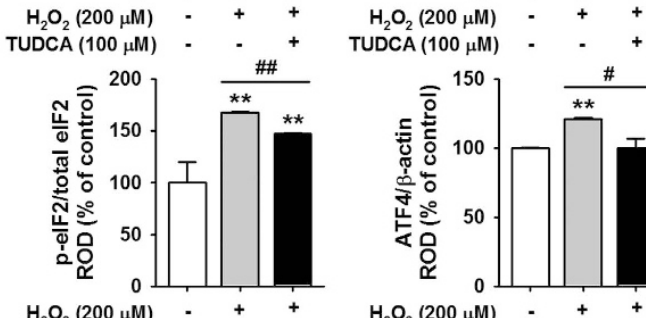

$\mathrm{H}_{2} \mathrm{O}_{2}(200 \mu \mathrm{M})$ TUDCA $(100 \mu \mathrm{M})$
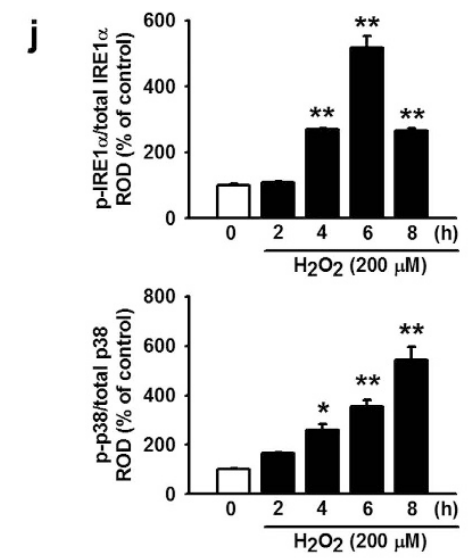

I

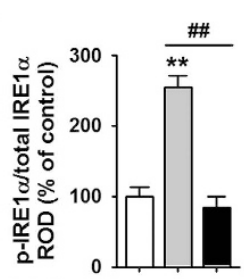

$\mathrm{H}_{2} \mathrm{O}_{2}(200 \mu \mathrm{M})-+$

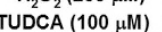

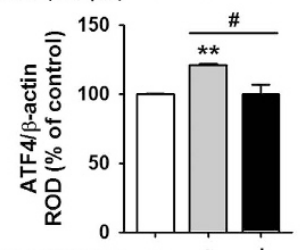

$\mathrm{H}_{2} \mathrm{O}_{2}(200 \mu \mathrm{M}) \div+$ TUDCA $(100 \mu \mathrm{M})$ - . + g

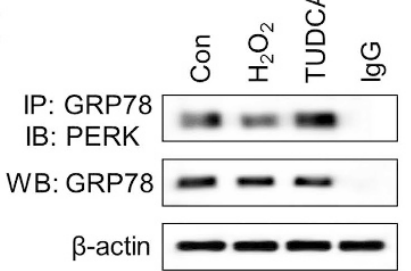

h

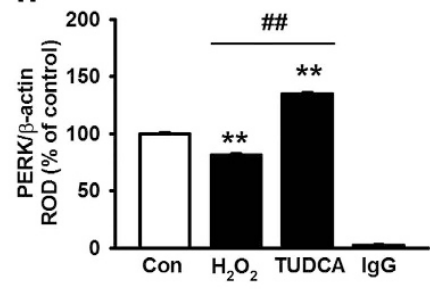

Figure 2. Protective effect of TUCDA against ER oxidative stress in MSCs. (a) Western blot of GRP78, p-PERK, PERK, p-eIF2 $\alpha$, eIF2 $\alpha$, and ATF4 expression after treatment of MSCs with $\mathrm{H}_{2} \mathrm{O}_{2}$ for the indicated times. (b) These data were normalized to $\beta$-actin, PERK, or eIF $\alpha$, respectively. Values represent the mean \pm SEM. ${ }^{\star} P<0.05$ and ${ }^{* *} P<0.01$ vs. untreated MSCs. (c) Immunoprecipitates with anti-GRP78 were analyzed by western blot using an antibody that recognizes PERK. (d) The level of PERK, which binds GRP78, was normalized to that of $\beta$-actin. Values represent the mean \pm SEM. ${ }^{* *} P<0.01$ vs. untreated MSCs. 
(e) Western blot of GRP78, p-PERK, PERK, p-eIF2 $\alpha$, eIF2 $\alpha$, and ATF4 expression after treatment of TUDCApretreated MSCs with $\mathrm{H}_{2} \mathrm{O}_{2}$ for $8 \mathrm{~h}$. (f) These data were normalized to $\beta$-actin, PERK, or eIF2 $\alpha$, respectively. Values represent the mean \pm SEM. ${ }^{*} P<0.05$ and ${ }^{* *} P<0.01$ vs. untreated MSCs, ${ }^{\#} P<0.05$, and ${ }^{\# \#} P<0.01$ vs. treatment of MSCs with $\mathrm{H}_{2} \mathrm{O}_{2}$. (g) Immunoprecipitates with anti-GRP78 were analyzed by western blot using an antibody that recognizes PERK after treatment of TUDCA-pretreated MSCs with $\mathrm{H}_{2} \mathrm{O}_{2}(200 \mu \mathrm{M})$ for $8 \mathrm{~h}$. (h) The expression level of PERK, which binds GRP78, was normalized to that of $\beta$-actin. Values represent the mean \pm SEM. ${ }^{\star *} P<0.01$ vs. untreated MSCs (Con), ${ }^{\# \#} P<0.01$ vs. MSCs treated with $\mathrm{H}_{2} \mathrm{O}_{2}$. (i) Western blot of p-IRE1 $\alpha$, IRE1 $\alpha$, p-JNK, JNK, p-p38, p38, and CHOP expression after treatment of MSCs with $\mathrm{H}_{2} \mathrm{O}_{2}$ for the indicated times. (j) These data were normalized to IRE1 $\alpha$, JNK, p38, or $\beta$-actin, respectively. Values represent the mean \pm SEM. ${ }^{\star} P<0.05$ and ${ }^{\star *} P<0.01$ vs. untreated MSCs. (k) Western blot of $\mathrm{p}$-IRE1 $\alpha$, IRE1 $\alpha, \mathrm{p}$-JNK, JNK, p-p38, p38, and CHOP expression after treatment of TUDCA-pretreated MSCs with $\mathrm{H}_{2} \mathrm{O}_{2}$ for $8 \mathrm{~h}$.

(1) These data were normalized to IRE $1 \alpha$, JNK, p38, or $\beta$-actin, respectively. Values represent the mean \pm SEM. ${ }^{\star} P<0.05$ and ${ }^{* *} P<0.01$ vs. untreated MSCs, ${ }^{\# \#} P<0.01$ vs. treatment of MSCs with $\mathrm{H}_{2} \mathrm{O}_{2}$.

roles $\mathrm{PrP}^{\mathrm{C}}$ plays in the survival of transplanted stem cells may provide insights into the protection of MSCs and development of $\mathrm{PrP}^{\mathrm{C}}$-targeted therapeutics.

Tauroursodeoxycholic acid (TUDCA) is an endogenous hydrophilic tertiary bile acid produces in humans at a low level. TUDCA is approved by the U.S. Food and Drug Administration for use in biliary cirrhosis, and it is used effectively for cholestatic liver diseases ${ }^{11}$. Recent studies have revealed that TUDCA has an ameliorating effect on several diseases, including neurodegenerative diseases, osteoarthritis, vascular diseases, and diabetes $^{12-15}$. In addition, TUDCA regulates stem cell differentiation into various lineages such as adipogenic and osteogenic lineages ${ }^{16,17}$. Mechanistic studies indicate that TUDCA attenuates ER stress, prevents unfolded protein response dysfunction, and stabilizes mitochondria ${ }^{18}$. However, little is known about the molecular mechanism by which TUDCA protects cells from oxidative stress. In particular, the potential for TUDCA regulation of $\operatorname{PrP}^{\mathrm{C}}$ has not been investigated.

To clarify the effect of TUDCA on MSCs in ischemic conditions, we investigated whether TUDCA enhanced survival of MSCs in ischemia-induced ER stress conditions in vitro and in vivo. Results of this study reveal the mechanism by which TUDCA protects against oxidative stress by regulating Akt-dependent $\operatorname{PrP}^{\mathrm{C}}$ expression.

\section{Results}

ER stress induced cell death in a murine ischemic model. Ischemic-injured tissue induces ROS generation and oxidative stress, resulting in further induction of ER stress and transplanted-cell death ${ }^{19,20}$. To confirm ROS-mediated ER stress and cell death in ischemic tissue, ROS generation and cell apoptosis were assessed in ischemic-injured tissues, using a murine hindlimb ischemia model. At postoperative day 3, ROS levels were higher in ischemic-injured tissues than in normal tissues (Fig. 1a). In addition, TUNEL assay indicated that apoptotic cells were significantly higher in ischemic-injured tissues than in normal tissues (Fig. $1 \mathrm{~b}$ and c). To investigate ROS-mediated ER stress in ischemic conditions in vivo, the expression and activation of ER stress-associated proteins (78-kDa glucose-regulated protein (GRP78), protein kinase R-like endoplasmic reticulum kinase (PERK), eukaryotic initiation factor 2-alpha (eIF2 $\alpha$ ), activating transcription factor 4 (ATF4), inositol-requiring protein 1 alpha (IRE1 $\alpha$ ), c-Jun N-terminal kinase (JNK), p38, and CCAAT-enhancer-binding protein homologous protein $(\mathrm{CHOP})$ ) in normal and ischemic-injured tissues were determined by western blot analysis (Fig. 1c-f). At postoperative day 3, ischemic-injured tissues exhibited significantly higher expression levels of ER stress markers (GRP78, ATF4, and CHOP) and phosphorylation of ER stress regulators (PERK, eIF2 $\alpha$, IRE1 $\alpha$, JNK, and p38) than those in normal tissues (Fig. 1d and f). Moreover, cell death and apoptosis-associated proteins (BCL-2-associated X protein (Bax), cleaved caspase-3, and cleaved poly(ADP ribose) polymerase-1 (PARP-1)) were significantly higher in ischemic-injured tissues than in normal tissues (Fig. $1 \mathrm{~g}$ and $\mathrm{h}$ ). Ischemia increased tissue death (Fig. $1 \mathrm{~g}$ and $\mathrm{h}$ ). These results indicate that ischemic conditions trigger ROS generation, resulting in cell apoptosis through the induction of ER stress.

TUDCA attenuated ER stress and cell death in ischemic conditions. $\mathrm{H}_{2} \mathrm{O}_{2}$ is an ideal in vitro ER oxidative stress inducer. To analyze the mechanism underlying ROS-mediated ER stress in MSCs, the expression and activation of ER stress-associated proteins (GRP78, p-PERK, p-eIF2 $\alpha$, and ATF4) were confirmed in vitro after treatment with $\mathrm{H}_{2} \mathrm{O}_{2}(200 \mu \mathrm{M})$ for various times $(0,2,4,6$, and $8 \mathrm{~h})$. Western blot analysis showed that ER stress markers (GRP78 and ATF4) and regulators (p-PERK and p-eIF2 $\alpha$ ) were enhanced by $\mathrm{H}_{2} \mathrm{O}_{2}$-induced ROS (Fig. 2a and b). In particular, treatment with $\mathrm{H}_{2} \mathrm{O}_{2}$ significantly suppressed binding between GRP78 and PERK compared with that in untreated cells (Fig. $2 \mathrm{c}$ and d). To elucidate the protective effect of TUDCA on $\mathrm{H}_{2} \mathrm{O}_{2}$-induced ROS in MSCs, western blotting of GRP78, ATF4, p-PERK, and p-eIF2 $\alpha$ was performed in $\mathrm{H}_{2} \mathrm{O}_{2}$-treated MSCs in the presence and absence of TUDCA (Fig. 2e). In ischemic conditions, treatment with TUDCA (100 $\mu$ M) significantly inhibited the expression and activation of ER stress-associated proteins compared with those of untreated MSCs (Fig. 2f). Interestingly, TUDCA significantly blocked the $\mathrm{H}_{2} \mathrm{O}_{2}$-mediated dissociation of GRP78 and PERK (Fig. $2 \mathrm{~g}$ and $\mathrm{h}$ ). Moreover, the activation and expression of other ER stress-associated proteins (IRE1 $\alpha, \mathrm{JNK}, \mathrm{p} 38$, and $\mathrm{CHOP}$ ) were confirmed in vitro after treatment with $\mathrm{H}_{2} \mathrm{O}_{2}(200 \mu \mathrm{M})$ for various times $(0,2,4,6$, and $8 \mathrm{~h})$. The ER stress-mediated proteins (p-IRE1 $\alpha$, p-JNK, p-p38, and CHOP) were activated by $\mathrm{H}_{2} \mathrm{O}_{2}$-induced ROS (Fig. $2 \mathrm{i}$ and $\mathrm{j}$ ). However, treatment with TUDCA $(100 \mu \mathrm{M})$ significantly inhibited the activation of these proteins (Fig. $2 \mathrm{k}$ and $\mathrm{l}$ ). To determine the mechanism of ROS-induced apoptosis, apoptosis-associated proteins (B-cell lymphoma 2 (BCL-2), Bax, cleaved caspase-3, and cleaved PARP-1) were assessed in vitro after treatment with $\mathrm{H}_{2} \mathrm{O}_{2}(200 \mu \mathrm{M})$ for various times $(0,2,4,6$, and $8 \mathrm{~h})$. The anti-apoptotic protein BCL-2 decreased and pro-apoptotic proteins 


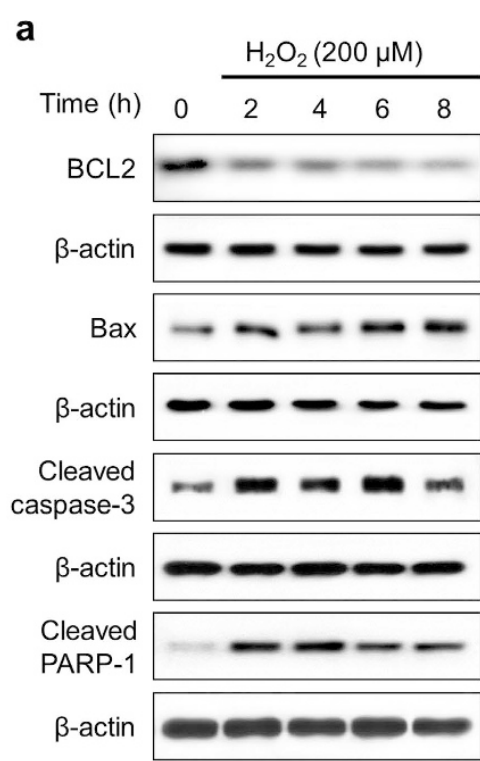

C

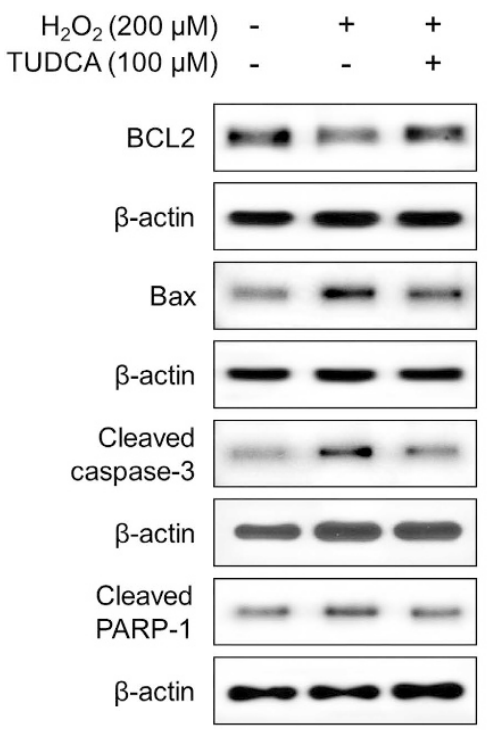

b
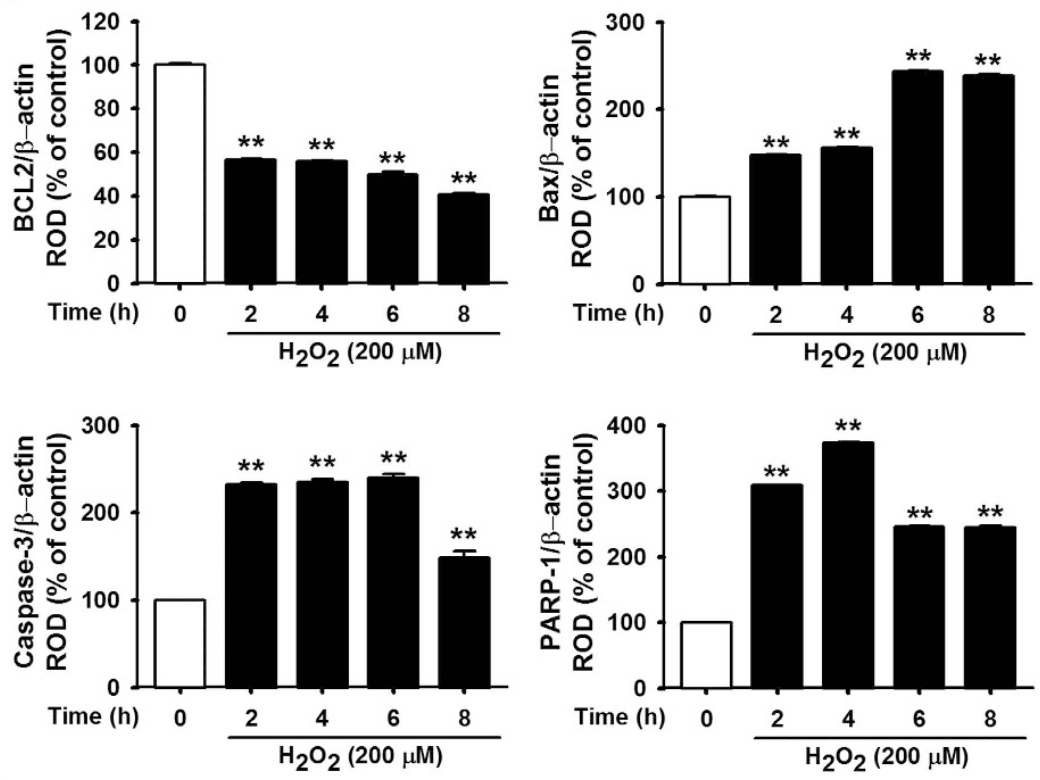

d
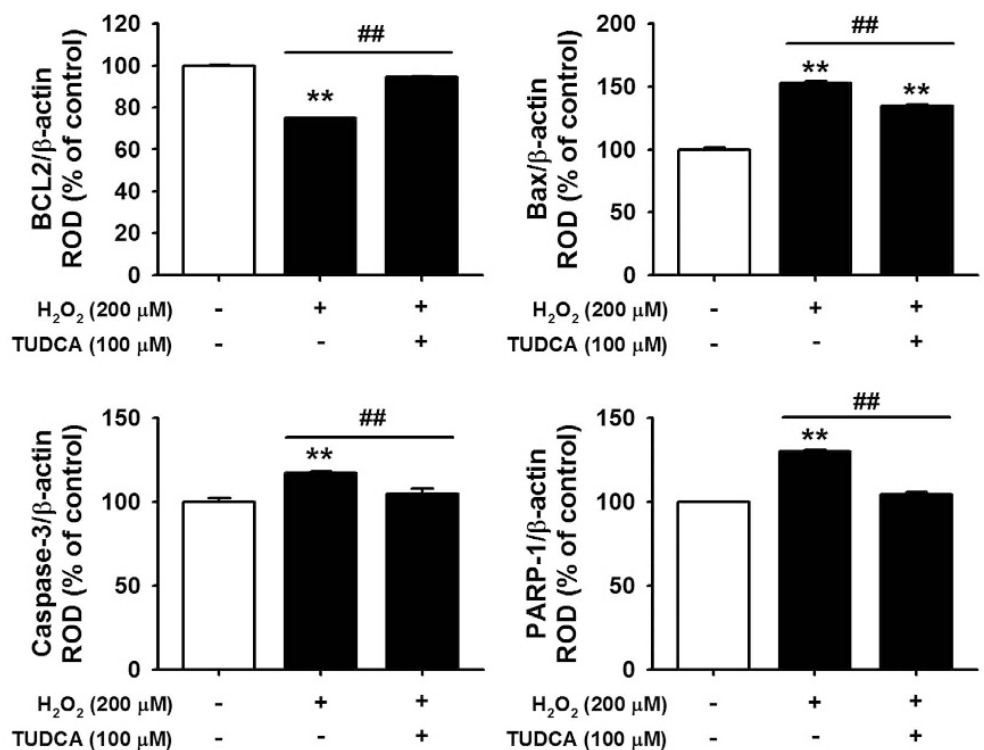

Figure 3. Protective effect of TUCDA against ER stress-induced apoptosis of MSCs. (a) Western blot analysis showing the expression of BCL-2, Bax, cleaved caspase-3, and cleaved PARP-1 after treatment of MSCs with $\mathrm{H}_{2} \mathrm{O}_{2}(200 \mu \mathrm{M})$ for the indicated times $(0,2,4,6$, or $8 \mathrm{~h})$. (b) The expression levels of BCL-2, Bax, cleaved caspase-3, and cleaved PARP-1 were normalized to that of $\beta$-actin. Values represent the mean \pm SEM. ${ }^{*} P<0.01$ vs. untreated MSCs. (c) Western blot analysis showing the expression of BCL-2, Bax, cleaved caspase-3, and cleaved PARP-1 after treatment of TUDCA-pretreated MSCs with $\mathrm{H}_{2} \mathrm{O}_{2}(200 \mu \mathrm{M})$ for $8 \mathrm{~h}$. (d) The expression levels of BCL-2, Bax, cleaved caspase-3, and cleaved PARP-1 were normalized to that of $\beta$-actin. Values represent the mean \pm SEM. ${ }^{* *} P<0.01$ vs. untreated MSCs, ${ }^{\# \#} P<0.01$ vs. MSCs treated with $\mathrm{H}_{2} \mathrm{O}_{2}$. Abbreviations: BCL-2, B-cell lymphoma 2.

Bax, cleaved caspase-3, and cleaved PARP-1 increased with ROS-mediated ER stress (Fig. 3a and b). To confirm TUDCA protection against ER stress-induced apoptosis, MSCs were pre-treated with TUDCA $(100 \mu \mathrm{M})$, and then apoptosis-associated protein levels were measured in $\mathrm{H}_{2} \mathrm{O}_{2}$-induced ER stress conditions (Fig. 3c). Under ER stress, treatment with TUDCA significantly increased the expression of BCL-2 and significantly decreased the expression of Bax, cleaved caspase-3, and cleaved PARP-1, compared with that of untreated cells (Fig. 3d). These findings indicate that treatment with TUDCA protects MSCs from ER stress-induced apoptosis by inhibiting the dissociation of GRP78 and PERK and regulating the apoptosis-associated signaling pathway. 
a

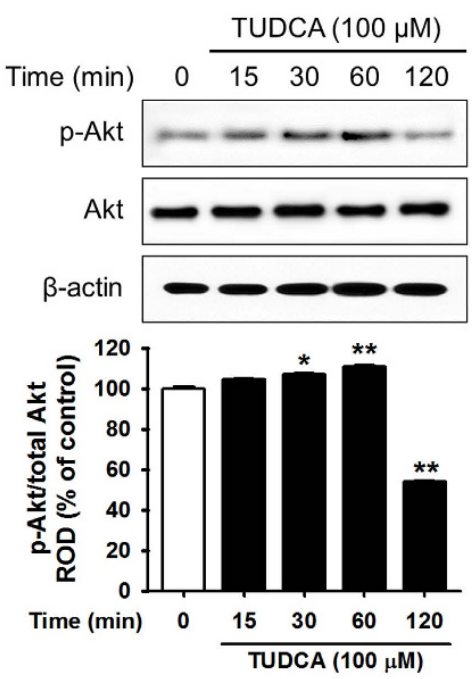

C

$\operatorname{TUDCA}(100 \mu \mathrm{M})-\quad+\quad+$ Akt inhibitor $\left(10^{-6} \mathrm{M}\right)$ - $\quad$ - +

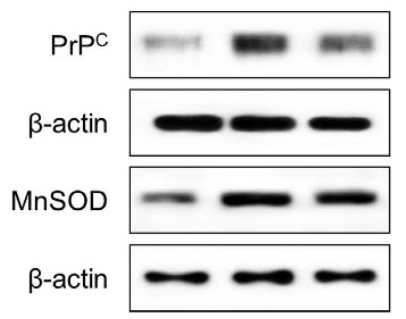

b

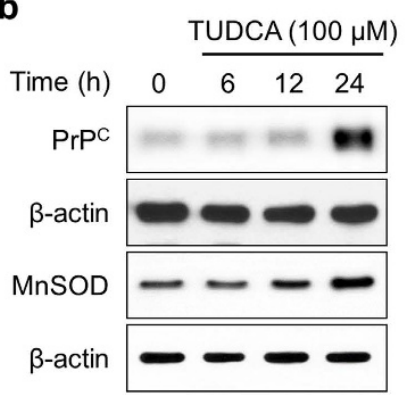

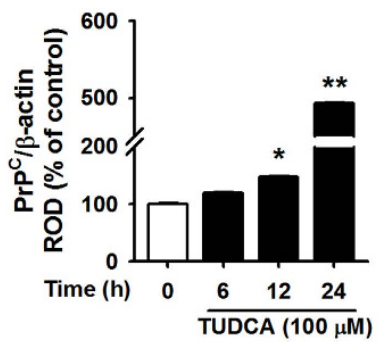

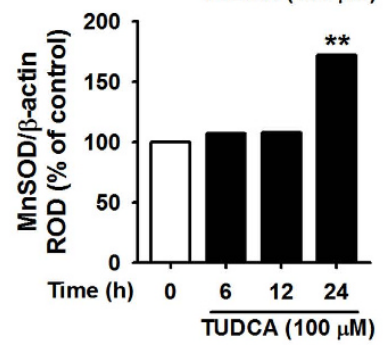

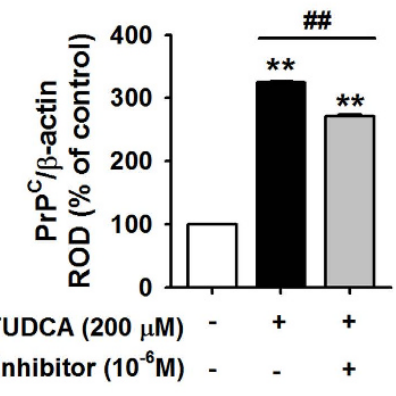

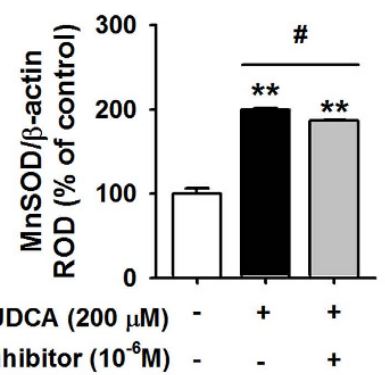

d

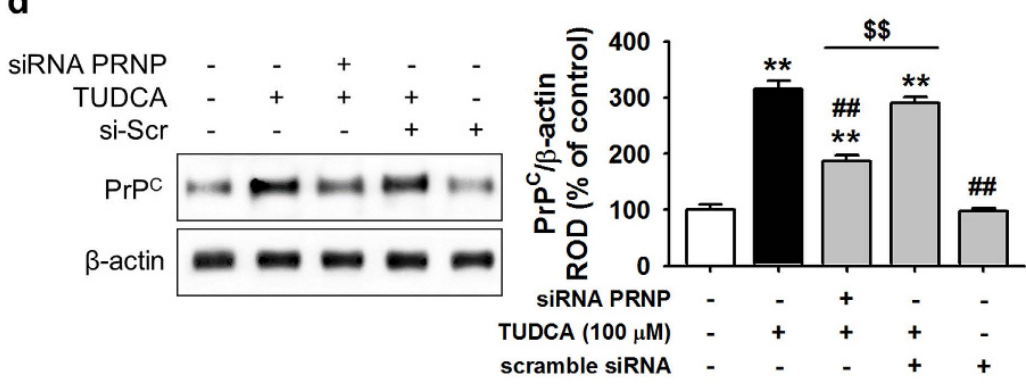

e

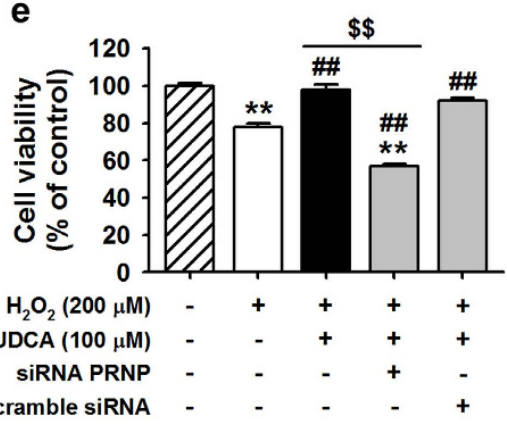

f
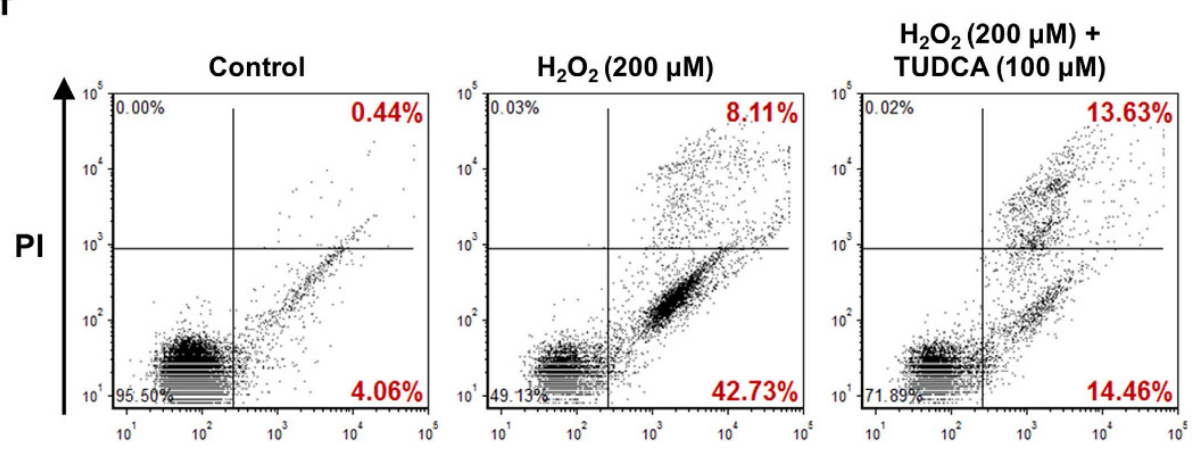

$\mathrm{H}_{2} \mathrm{O}_{2}(200 \mu \mathrm{M})+$ TUDCA $(100 \mu \mathrm{M})+$ si-PRNP

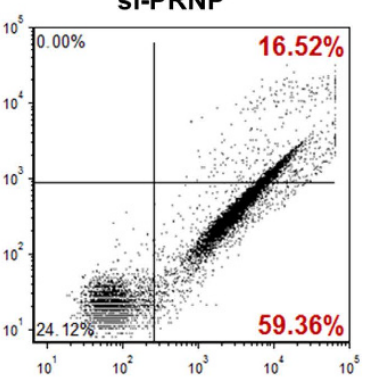

Annexin V

Figure 4. TUDCA inhibited $\mathrm{H}_{2} \mathrm{O}_{2}$-induced MSC apoptosis via Akt-dependent PrPC. (a) Western blot analysis of p-Akt expression after treatment of MSCs with TUDCA $(100 \mu \mathrm{M})$ for the indicated times $(0,15,30$, 60 , or $120 \mathrm{~min})$. The lower panel shows the expression levels of p-Akt normalized to that of total Akt. Values represent the mean \pm SEM. ${ }^{\star} P<0.05$ and ${ }^{\star *} P<0.01$ vs. untreated MSCs. (b) Western blot analysis of $\operatorname{Pr}^{\mathrm{C}}$ and MnSOD expression after treatment of MSCs with TUDCA $(100 \mu \mathrm{M})$ for the indicated times $(0,6,12$, or $24 \mathrm{~h})$. The right panel shows the expression levels of $\operatorname{PrP}^{\mathrm{C}}$ and MnSOD normalized to that of $\beta$-actin. Values represent the mean \pm SEM. ${ }^{\star} P<0.05$ and ${ }^{* *} P<0.01$ vs. untreated MSCs. (c) Western blot analysis of $\operatorname{PrP}^{\mathrm{C}}$ and 
MnSOD expression after treatment of Akt inhibitor $\left(10^{-6} \mathrm{M}\right)$-pretreated MSCs with TUDCA $(100 \mu \mathrm{M})$ for $24 \mathrm{~h}$. The right panel shows the expression levels of $\mathrm{PrP}^{\mathrm{C}}$ and $\mathrm{MnSOD}$ normalized to $\beta$-actin. Values represent the mean \pm SEM. ${ }^{* *} P<0.01$ vs. untreated MSCs, ${ }^{\#} P<0.05$ and ${ }^{\# \#} P<0.01$ vs. Akt inhibitor-pretreated MSCs treated with TUDCA. (d) Western blot analysis of $\operatorname{PrP}^{\mathrm{C}}$ expression after treatment of PRNP siRNA-pretreated MSCs with TUDCA $(100 \mu \mathrm{M})$ for $24 \mathrm{~h}$. The right panel shows the expression levels of $\operatorname{PrP}^{\mathrm{C}}$ normalized to that of $\beta$-actin. Values represent the mean \pm SEM. ${ }^{\star *} P<0.01$ vs. untreated MSCs, ${ }^{\# \#} P<0.01$ vs. treatment of MSCs with TUDCA, ${ }^{\$} P<0.01$ vs. TUDCA-treated MSCs pretreated with scramble siRNA. (e) Under oxidative stress conditions (induced by treatment with $\mathrm{H}_{2} \mathrm{O}_{2}$ ), cell viabilities of untreated MSCs, TUDCA-treated MSCs, and TUDCA-treated MSCs pretreated with PRNP-specific siRNA were assessed by MTT assay. Values represent the mean \pm SEM. ${ }^{* *} P<0.01$ vs. untreated MSCs in non-oxidative conditions, ${ }^{\# \#} P<0.01$ vs. untreated MSCs in oxidative stress conditions, ${ }^{\$} P<0.01$ vs. TUDCA-treated MSCs in oxidative conditions. (f) Survival and apoptosis were measured using PI/Annexin V staining and flow cytometric analysis. Abbreviations: Akt, protein kinase B; MnSOD, manganese-dependent superoxide dismutase; PRNP, human PrP gene; Scr, scramble.

TUDCA mediates ER stress resistance via the expression of Akt-dependent PrPC. A previous study revealed that $\mathrm{PrP}^{\mathrm{C}}$ promotes post-ischemic neuronal survival and neurogenesis in brain ischemia ${ }^{8}$. In considering how TUDCA protects against ER stress, we hypothesized that the TUDCA-related Akt signaling pathway regulates $\mathrm{PrP}^{\mathrm{C}}$ and $\mathrm{MnSOD}$. First, we analyzed the response of the Akt signaling pathway to treatment of human adipose tissue-derived MSCs with TUDCA. In a western blot analysis, treatment of MSCs with TUDCA increased phosphorylation of Akt within $30 \mathrm{~min}$ of treatment (Fig. 4a). To determine whether TUDCA plays a role in the regulation of Akt-mediated protein expression, the expression levels of $\mathrm{PrP}^{\mathrm{C}}$ and MnSOD were investigated after treatment with TUDCA for various times $(0,6,12$, and $24 \mathrm{~h})$. After $24 \mathrm{~h}$ of treatment, the expression levels of $\mathrm{PrP}^{\mathrm{C}}$ and MnSOD dramatically increased, and expression of these proteins was suppressed by the use of an Akt inhibitor (Fig. $4 \mathrm{~b}$ and c). To further explore whether TUDCA-related $\mathrm{PrP}^{\mathrm{C}}$ expression ameliorates cell death in ROS-induced ER stress, a cell viability assay was performed under oxidative stress conditions using PRNP siRNA, which is an siRNA targeting the human PrP gene (Fig. 4d). In $\mathrm{H}_{2} \mathrm{O}_{2}$-induced ER stress conditions, treatment of MSCs with TUDCA significantly enhanced cell viability compared with that in the non-treatment group, while pre-treatment with PRNP siRNA significantly decreased cell viability compared with that in the TUDCA treatment and non-treatment groups (Fig. 4e). In addition, flow cytometric analysis of PI and Annexin $\mathrm{V}$ indicated that downregulation of $\mathrm{PrP}^{\mathrm{C}}$ increased cell death in $\mathrm{H}_{2} \mathrm{O}_{2}$-induced ER stress conditions (Fig. 4f). These findings suggest that the protective effect of TUDCA on cells under ER stress is mediated by the Akt-PrPC and MnSOD pathways, and that this mechanism may be $\mathrm{PrP}^{\mathrm{C}}$-dependent.

TUDCA-treated MSCs enhance functional recovery in murine hindlimb ischemia via PrP ${ }^{C}$ To assess whether TUDCA-treated MSCs increase neovascularization in vivo, blood perfusion and tissue repair were investigated following transplantation of PBS, untreated MSCs (MSC), TUDCA-treated MSCs (TUDCA), TUDCA-treated MSCs pretreated with PRNP-specific siRNA (TUDCA + siPRNP), and TUDCA-treated MSCs pretreated with scramble siRNA into hindlimb ischemia mice. Blood perfusion was analyzed by LDPI at postoperative days $0,3,7,14,21$, and 28 (Fig. $5 \mathrm{a}$ ). The blood perfusion ratio was significantly greater in the TUDCA-treated MSC group than in the other groups (Fig. 5b). Moreover, transplantation of TUDCA-treated MSCs resulted in a reduction in limb loss and foot necrosis (Fig. $5 \mathrm{c}$ and d), and transplantation of TUDCA-treated MSCs pretreated with PRNP-specific siRNA decreased functional recovery. To evaluate the anti-oxidative effect of TUDCA-treated MSCs in ischemic conditions, the expression of MnSOD in ischemic-injured sites was assessed by immunohistochemistry after transplantation of MSCs. Prior to the in vivo studies, catalase activity of MSCs in ischemic conditions was assessed in vitro to determine whether treatment of MSCs with TUDCA augmented MnSOD activity. Treatment with TUDCA significantly increased catalase activity, but this activity was significantly decreased by $\mathrm{PrP}^{\mathrm{C}}$ protein inhibition (Fig. 6a). At postoperative day 1, immunohistochemistry for MnSOD indicated that the expression of MnSOD in ischemic-injured sites was higher in TUDCA-treated transplanted MSCs than that in other groups (Fig. 6b). To confirm apoptosis of transplanted MSCs in ischemic sites, immunohistochemistry for HNA and cleaved caspase-3 was performed at postoperative day 3 (Fig. 6c). Apoptosis of transplanted MSCs was significantly lower in the TUDCA-treated group than in other groups (Fig. 6d). To investigate neovascularization by transplanted MSCs, immunohistochemistry for CD31 or $\alpha$-SMA was performed at postoperative day 28 (Fig. 6e-h). Capillary density and arteriole density were significantly higher in transplanted TUDCA-treated MSCs than in the other groups (Fig. 6e-h). Inhibition of $\operatorname{PrP}^{\mathrm{C}}$ protein significantly decreased the expression of MnSOD, cell survival, and vascular formation. These data indicated that TUDCA-treated MSCs facilitated vascular repair and functional recovery in ischemic-injured tissues, and that TUDCA-mediated $\operatorname{PrP}^{\mathrm{C}}$ plays a pivotal role in the functionality of transplanted MSCs in these tissues.

\section{Discussion}

Recent preclinical animal studies and clinical trials have shown that autologous and allogeneic MSCs from various sources transplanted into ischemic-injured sites localize to injured tissues ${ }^{21}$. However, transplanted MSCs can die in ischemic tissues, largely as a result of pathophysiological conditions such as low oxygen, high ROS levels, and inflammation ${ }^{22}$. This study is the first to demonstrate that TUDCA effectively protects MSCs against ER stress-related cell death and improves functional recovery of vessels through an Akt-dependent $\operatorname{PrP}^{\mathrm{C}}$ signaling cascade in vivo and in vitro.

Our findings indicate that ischemic injury induces ROS generation, and that GRP78, PERK, eIF2 $\alpha$, and ATF4 are subsequently activated, resulting in the induction of ER stress mediated-apoptosis cascades. ER stress 
a

Day

BS

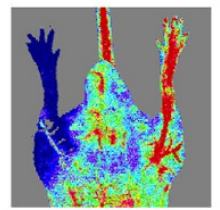

MSC

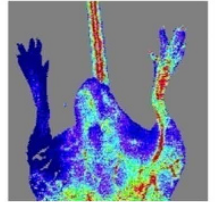

TUDCA

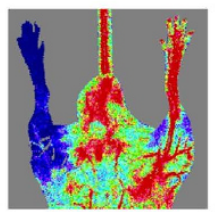

TUDCA

+ si-PRNP

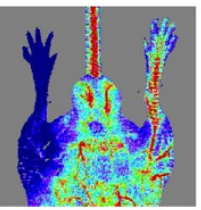

Scramble si-RNA

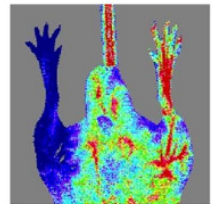

3
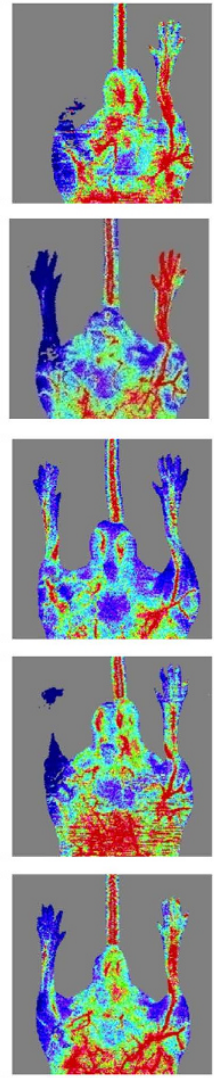

7
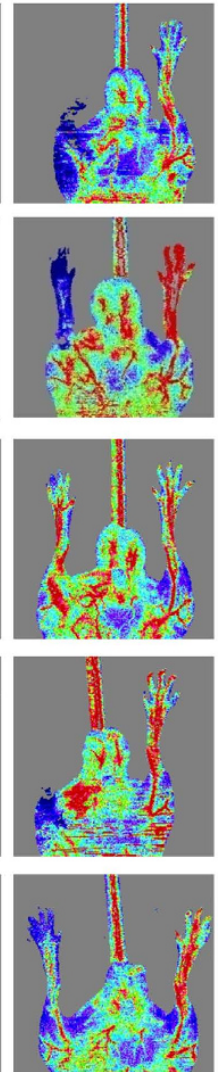

14
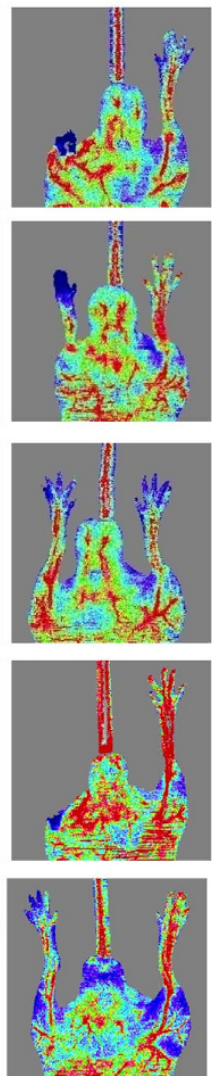

21
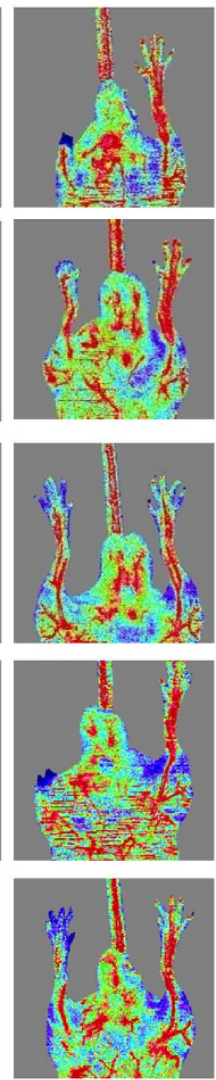

28
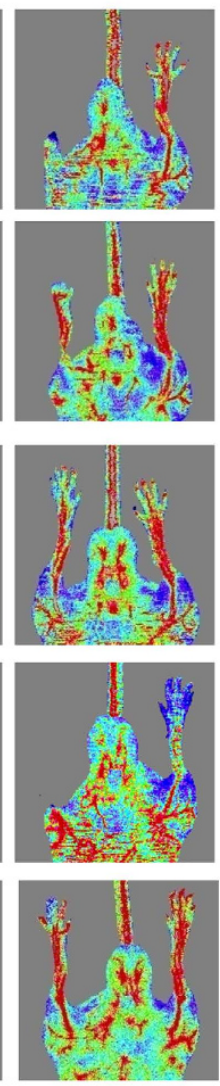

b

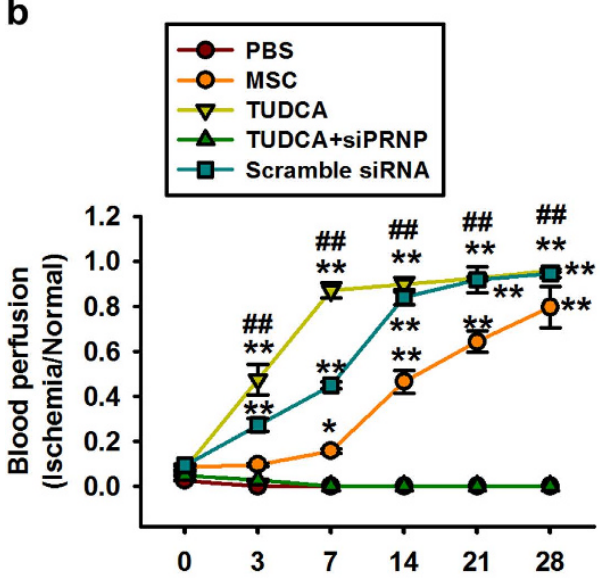

C

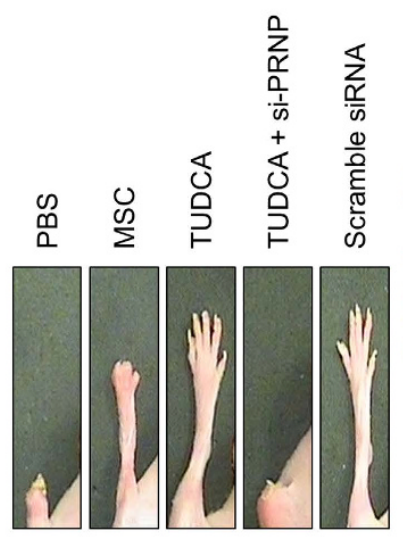

d

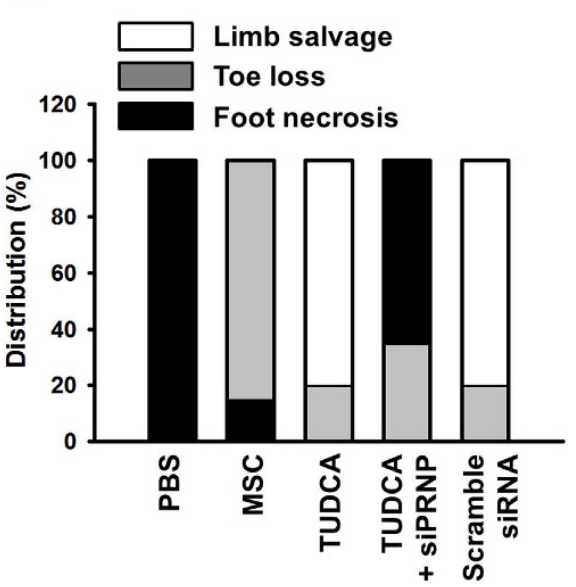

Figure 5. Assessment of functional recovery in a murine hindlimb ischemia model. (a) The murine hindlimb ischemia model was established through ligation of the proximal femoral artery and boundary vessels of 8-week-old male Balb/C nude mice. Improvements in blood perfusion were assessed by laser Doppler perfusion imaging analysis of the ischemic-injured tissues of mice injected with PBS, MSCs (MSC), TUDCAtreated MSCs (TUDCA), TUDCA-treated MSCs pretreated with PRNP-specific siRNA (TUDCA + siPRNP), and TUDCA-treated MSCs pretreated with scramble siRNA at 0 days, 3 days, 7 days, 14 days, 21 days, and 28 days postoperation. (b) The ratio of blood perfusion (blood flow in the left ischemic limb/blood flow in the right non-ischemic limb) was measured in each of the five groups. Values represent the mean \pm SEM. ${ }^{*} P<0.05$ and ${ }^{* *} P<0.01$ vs. $P B S,{ }^{\# \#} P<0.01$ vs. TUDCA. (c) Representative images illustrating the different outcomes (foot necrosis, toe loss, and limb salvage) of ischemic limbs injected with five treatments at postoperative day 28 . (d) Distribution of the outcomes in each group at postoperative day 28. 
a

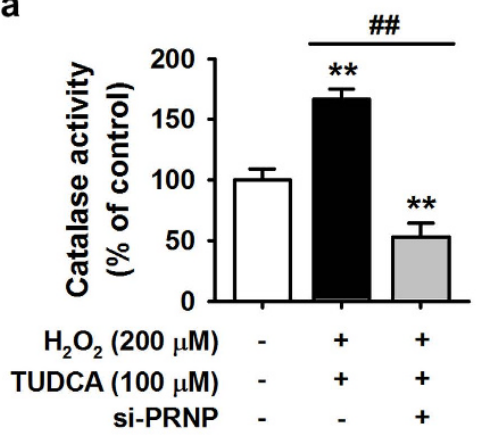

C

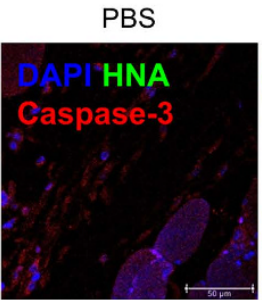

MSC

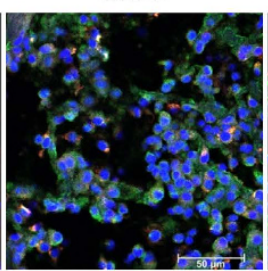

TUDCA-MSC
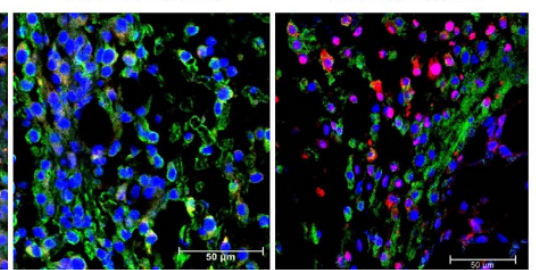

d

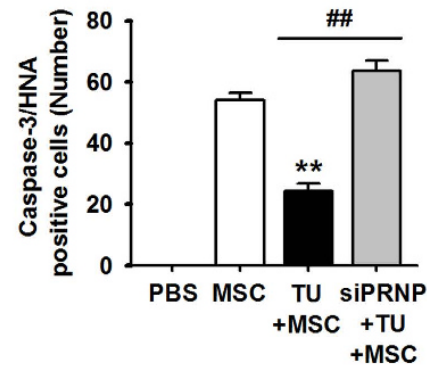

e PBS

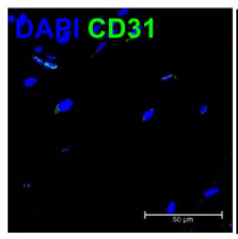

MSC

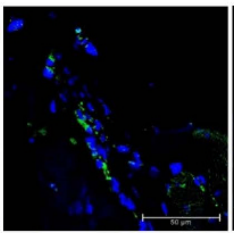

TUDCA-MSC

SiPRNP + Scramble siRNA +
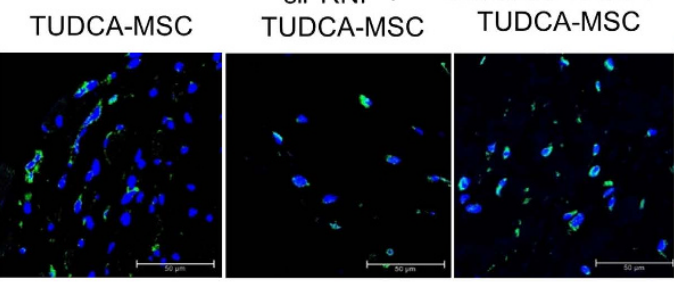

$f$

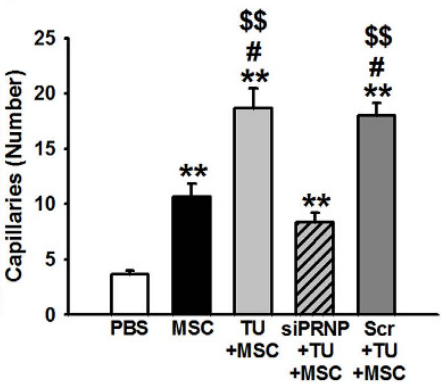

g

PBS

MSC
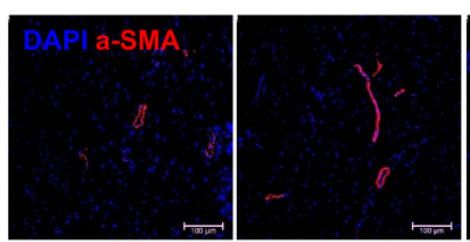

h

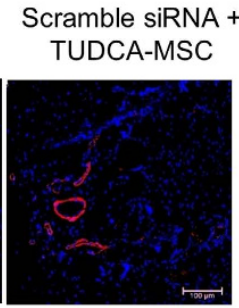

si-PRNP + TUDCA-MSC

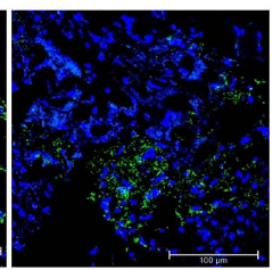

+ MSC

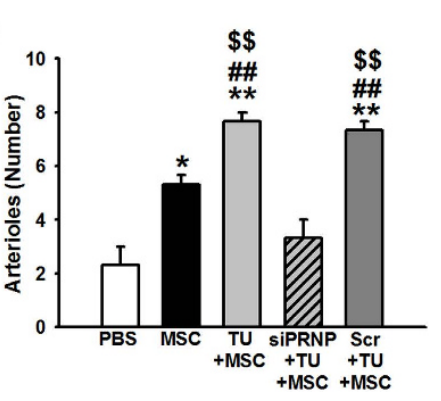

Figure 6. TUDCA-treated MSCs enhance functional recovery in murine hindlimb ischemia. (a) In oxidative stress conditions (treatment with $\mathrm{H}_{2} \mathrm{O}_{2}$ ), TUDCA-mediated catalase activity in MSCs was assessed by determining the expression levels of $\operatorname{PrP}^{\mathrm{C}}$. Values represent the mean \pm SEM. ${ }^{* *} P<0.01$ vs. untreated MSCs in non-oxidative condition, ${ }^{\#} P<0.01$ vs. TUDCA-treated MSCs pretreated with PRNP-specific siRNA under oxidative stress conditions. (b) At postoperative day 1, immunofluorescence staining for MnSOD (green) was performed in the ischemic-injured tissues of each group. Scale bar $=100 \mu \mathrm{m}$. (c) At postoperative day 3 , apoptosis of transplanted MSCs was investigated by immunofluorescence staining for HNA (green) and cleaved caspase-3 (red). Scale bar $=50 \mu \mathrm{m}$. (d) Apoptotic transplanted MSCs were quantified based on the number of HNA and PCNA double-positive cells. Values represent the mean \pm SEM. ${ }^{\star \star} P<0.01$ vs. transplantation of

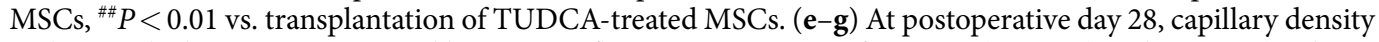
and arteriole density were assessed by immunofluorescence staining for CD31 (green; e) and $\alpha$-SMA (Red; g), respectively. Scale bar $=50 \mu \mathrm{m}, 100 \mu \mathrm{m}$. Capillary density (f) and arteriole density (h) were quantified as the number of CD31 and $\alpha$-SMA positive cells, respectively. Values represent the mean \pm SEM. ${ }^{\star} P<0.05$ and ${ }^{* *} P<0.01$ vs. injection of PBS, ${ }^{\#} P<0.05$ and ${ }^{\#} P<0.01$ vs. transplanted MSCs, ${ }^{\$} P<0.01$ vs. transplantation of TUDCA-treated MSCs pretreated with PRNP-specific siRNA. 
is caused by nutrient deprivation, hypoxic injury, redox and glycosylation reactions, and disturbances in calcium mobilization ${ }^{23}$. GRP78, an ER chaperone, plays a pivotal role in cell survival and death via interactions with PERK, which regulates eIF2 $\alpha$ and the ATF4 signaling pathway ${ }^{24}$. In non-stress conditions, GRP78 binds to PERK, causing it to remain inactive, but ER stress causes GRP78 to dissociate from PERK, and this activation of PERK leads to eIF2 $\alpha$ and ATF4 activation, resulting in cell death ${ }^{25}$. In addition, we found that TUDCA inhibits the activation of ER stress-mediated pro-apoptotic mediators, such as IRE1 $\alpha$, JNK, p38, and CHOP, under oxidative stress conditions. IRE1, as an ER transmembrane sensor, triggers ER stress-associated apoptosis through the decay of anti-apoptotic miRNA ${ }^{26}$. IRE1 also regulates the determination of cell fate via phosphorylation of JNK under ER stress conditions ${ }^{27}$. ER stress increases the activation of JNK and $\mathrm{p} 38^{28}$. Furthermore, the apoptosis-related transcription factor $\mathrm{CHOP}$, which promotes the expression of apoptotic genes such as cell surface death receptor 5 and $\mathrm{BH} 3$-only protein BIM, is regulated by the PERK-eIF2 $\alpha$-ATF4 pathway under ER stress conditions, resulting in the induction of apoptosis ${ }^{29}$. Our results show that TUDCA inhibits the dissociation of GRP78 from PERK during ER stress, preventing the activation of eIF2 $\alpha$ and ATF4. This suggests that TUDCA protects cells from ER stress by regulating the binding of GRP78 to PERK.

Our results show that TUDCA facilitates expression of $\mathrm{PrP}^{\mathrm{C}}$ in MSCs. $\mathrm{PrP}^{\mathrm{C}}$ has a protective effect on cells in conditions of hypoxia, ischemia, and excitotoxicity ${ }^{30-32} \cdot \operatorname{PrP}^{\mathrm{C}}$ promotes long-term neuroprotection and angiogenesis in the ischemic brain ${ }^{8,33}$. $\mathrm{PrP}^{\mathrm{C}}$ deficiency increases sensitivity to oxidative stress and aggravates brain ischemia ${ }^{34-36}$. In particular, downregulation of $\mathrm{PrP}^{\mathrm{C}}$ increases phosphorylation of extracellular signal-regulated kinases $1 / 2$ and reduces the activation of Akt, resulting in an increase in caspase- 3 activity $^{36}$. In addition, enhancement of Akt-mediated MnSOD expression promotes protection of MSCs against oxidative stress in vitro and in vivo ${ }^{37}$. Akt is a central cell signaling molecule downstream to cytokines, growth factors, and several stimulations ${ }^{38}$. Various stimuli induce the phosphorylation of Akt, thus activating it to regulate cellular functions such as survival, growth, proliferation, angiogenesis, metabolism, glucose uptake, migration, and invasion ${ }^{38}$. Under ER stress conditions, TUDCA decreases the activity of protein tyrosine phosphatase $1 \mathrm{~B}$, resulting in activation of the PI3K-Akt signal pathway and subsequently, the inhibition of ER stress ${ }^{39}$. This study, for the first time, showed that TUDCA decreased apoptosis signaling and increased cell viability under ischemic conditions via regulation of Akt-dependent PrPC expression. TUDCA-induced phosphorylation of Akt enhanced the expression of both $\mathrm{PrP}^{\mathrm{C}}$ and $\mathrm{MnSOD}$, thus augmenting the catalase activity. However, inhibition of the Akt pathway blocked TUDCA-induced expression of $\mathrm{PrP}^{\mathrm{C}}$ and MnSOD. Interestingly, knockdown of $\mathrm{PrP}^{\mathrm{C}}$ did not protect against ER stress-mediated cell death. These findings indicate that TUDCA protects MSCs against ER stress through the Akt-dependent $\mathrm{PrP}^{\mathrm{C}}$ signaling pathway and Akt-dependent MnSOD expression and suggest that activation of $\mathrm{PrP}^{\mathrm{C}}$ is a key mechanism underlying TUDCA-mediated ER stress protection.

Finally, this study showed that TUDCA-treated MSCs enhanced functional recovery and neovascularization in a murine hindlimb ischemia model. Blood flow ratio, limb salvage, expression levels of MnSOD, transplanted cell survival, and vessel repair were all increased following transplantation of TUDCA-treated MSCs and were mediated by $\operatorname{PrP}^{\mathrm{C}}$ expression. $\operatorname{PrP}^{\mathrm{C}}$ knockout mice showed severe renal dysfunction and structural damage following renal ischemia/reperfusion injury ${ }^{40}$. Our results indicate that TUDCA-treated MSCs have enhanced bioactivities, and that transplantation of TUDCA-treated MSCs could be used in stem cell-based therapeutics for ischemic diseases. In summary, this study, for the first time, demonstrated that TUDCA protects MSCs against ROS-mediated ER stress through the Akt-dependent $\operatorname{PrP}^{\mathrm{C}}$ signaling pathway, which suggests that activation of $\mathrm{PrP}^{\mathrm{C}}$ is a crucial mechanism for TUDCA-mediated MSC protection. These findings also suggest that TUDCA-treated MSCs may offer new therapeutics for ischemic disease, and that understanding the regulation of $\mathrm{PrP}^{\mathrm{C}}$ may provide important insights survival mechanisms of transplanted cells that will facilitate successful cell engraftment.

\section{Methods}

Human MSC cultures. Human adipose tissue-derived MSCs were obtained from the American Type Culture Collection (Manassas, VA, USA). MSCs were free of hepatitis B virus, hepatitis C virus, human immunodeficiency virus, and syphilis) and negative for mycoplasma. The supplier certified that the MSCs expressed MSC surface markers (CD73 and CD105) and showed adipogenic and osteogenic differentiation potential when cultured with specific differentiation media. MSCs were cultured in alpha-Minimum Essential Medium ( $\alpha$-MEM; Gibco BRL, Gaithersburg, MD, USA) supplemented with 10\% (v/v) fetal bovine serum (FBS; Gibco BRL) and $100 \mathrm{U} / \mathrm{mL}$ penicillin/streptomycin (Gibco BRL). MSCs were incubated in a humidified incubator at $37^{\circ} \mathrm{C}$ and $5 \% \mathrm{CO}_{2}$.

Chemical treatment of MSCs. MSCs were washed twice with phosphate buffer saline (PBS), and fresh $\alpha$-MEM supplemented with $10 \%$ FBS was added. To investigate the apoptosis signaling pathway, MSCs were pretreated with TUDCA $(100 \mu \mathrm{M})$ at $37^{\circ} \mathrm{C}$ for $30 \mathrm{~min}$ and then treated with $\mathrm{H}_{2} \mathrm{O}_{2}(200 \mu \mathrm{M})$ for various times $(0,2,4,6$, or $8 \mathrm{~h})$. To assess another cell signaling pathway, MSCs were treated with an Akt inhibitor $\left(10^{-6} \mathrm{M}\right.$; Sigma, St. Louis, MO) for $30 \mathrm{~min}$ at $37^{\circ} \mathrm{C}$ before treatment with TUDCA.

Ethics statement. The Institutional Animal Care and Use Committee of Soonchunhyang University approved all surgical interventions and postoperative animal care (IACIC2013-5). Experiments were performed on 8-week-old male Balb/C nude mice (Biogenomics, Seoul, Korea) maintained in a 12-h light/dark cycle in accordance with the regulations of Soonchunhyang University, Seoul Hospital.

Murine hindlimb ischemia model. To induce ischemia and oxidative stress and to assess neovascularization, a previously described hindlimb ischemia model was used with minor modifications ${ }^{41,42}$. Ischemia was induced by ligation of the proximal femoral artery and boundary vessels of the mice. No later than $6 \mathrm{~h}$ after surgery, 
PBS, MSCs, TUDCA-treated MSCs, and TUDCA-treated MSCs with scramble or human PrP gene (PRNP) small interfering RNA (siRNA) were injected intramuscularly into the ischemic thigh area $\left(5 \times 10^{5} \mathrm{cells} / 80 \mu \mathrm{L}\right.$ PBS per mouse; $n=5$ for each group). Cells were injected into four ischemic sites. Blood perfusion was investigated by measuring the ratio of blood flow in the ischemic (left) limb to that in the non-ischemic (right) limb on postoperative days $0,3,7,14,21$, and 28 using laser Doppler perfusion imaging (LDPI; Moor Instruments, Wilmington, DE).

Immunohistochemistry. After 1, 3, and 28 days following operation, the ischemic thigh tissues were removed and fixed with $4 \%$ paraformaldehyde (Sigma). Each tissue sample was embedded in paraffin. Immunofluorescence staining was performed using primary antibodies against human nuclear antigen (HNA; Millipore, Billerica, MA, USA), manganese-dependent superoxide dismutase (MnSOD; Santa Cruz Biotechnology, Santa Cruz, CA, USA), cleaved caspase-3 (Santa Cruz Biotechnology), CD31 (Santa Cruz Biotechnology), and $\alpha$-SMA (Santa Cruz Biotechnology) and secondary antibodies Alexa-488 and Alexa-594 (Thermo Fisher Scientific, Waltham, MA, USA). Nuclei were stained with 4',6-diaminido-2-phenylindol (DAPI; Sigma), and immunostained samples were observed using confocal microscopy (Olympus, Tokyo, Japan).

Dihydroethidium (DHE) staining. DHE (Sigma) was used to measure superoxide anion levels in the ischemic thigh sections. The sections were immersed in DHE $(10 \mu \mathrm{M})$ for $30 \mathrm{~min}$ at $37^{\circ} \mathrm{C}$. After washing with PBS three times, samples were visualized by confocal microscopy (Olympus) at $488 \mathrm{~nm}$ excitation and $590 \mathrm{~nm}$ emission.

TUNEL assay. The terminal deoxynucleotidyl transferase-mediated dUTP nick end labeling (TUNEL) assay was performed using a TdT Fluorescein In Situ Apoptosis Detection Kit (Trevigen, Inc, Gaithersburg, MD, USA). The MSCs were pre-treated with TUDCA ( $15 \mathrm{~min}$ ) and then treated with $\mathrm{H}_{2} \mathrm{O}_{2}$ for $6 \mathrm{~h}$. Next, MSCs were labeled according to the manufacturer's instructions. Stained MSCs were visualized using a fluorescence microscope (ZEISS, Oberkochen, Germany).

Western blot assay. The MSC homogenates $(20 \mu \mathrm{g}$ protein) were separated via $8-12 \%$ sodium dodecyl sulfate-polyacrylamide gel electrophoresis (SDS-PAGE), and the proteins were transferred to nitrocellulose. After the blots had been washed with TBST (10 mM Tris- $\mathrm{HCl}$ [pH 7.6], $150 \mathrm{mM} \mathrm{NaCl}, 0.05 \%$ Tween-20), the membranes were blocked with $5 \%$ skim milk for $1 \mathrm{~h}$ and incubated with the appropriate primary antibodies at the dilutions recommended by the supplier. Antibodies against GRP78, PERK, p-PERK, eIF2 $\alpha$, p-eIF2 $\alpha$, ATF4, IRE1 $\alpha$, p-IRE1 $\alpha$, JNK, p-JNK, p38, p-p38, CHOP, BCL-2, Bax, cleaved caspase-3, cleaved PARP-1, Akt, phosphor-Akt, $\operatorname{PrP}^{\mathrm{C}}, \alpha$-tubulin, and $\beta$-actin were all purchased from Santa Cruz Biotechnology. The membranes were then washed, and the primary antibodies were detected using goat anti-rabbit IgG or goat anti-mouse IgG conjugated to horseradish peroxidase (Santa Cruz Biotechnology). The bands were visualized by enhanced chemiluminescence (Amersham Pharmacia Biotech, England, UK).

Immunoprecipitation. MSCs were lysed with a lysis buffer (1\% Triton X-100 in $50 \mathrm{mM}$ Tris- $\mathrm{HCl}$ [pH 7.4] containing $150 \mathrm{mM} \mathrm{NaCl}, 5 \mathrm{mM}$ EDTA, $2 \mathrm{mM} \mathrm{Na}_{3} \mathrm{VO}_{4}, 2.5 \mathrm{mM} \mathrm{Na}_{4} \mathrm{PO}_{7}, 100 \mathrm{mM} \mathrm{NaF}$, and protease inhibitors). Cell lysates $(300 \mu \mathrm{g})$ were mixed with anti-GRP78 antibody (Santa Cruz Biotechnology). The samples were incubated for $4 \mathrm{~h}$, mixed with Protein A/G PLUS-Agarose Immunoprecipitation Reagent (Santa Cruz Biotechnology), and then incubated for an additional $12 \mathrm{~h}$. The beads were washed four times, and the bound protein was released from the beads by boiling in SDS-PAGE sample buffer for $5 \mathrm{~min}$. The precipitated proteins were analyzed by western blotting with anti-PERK antibody (Santa Cruz Biotechnology).

Inhibition of PrPC expression by RNA interference. MSCs $\left(2 \times 10^{5}\right)$ were seeded in 60 -mm dishes and were transfected with siRNA in serum-free Opti-MEM (Gibco BRL) using Lipofectamine 2000, following the manufacturer's instructions (Thermo Fisher Scientific). At $48 \mathrm{~h}$ after transfection, total protein was extracted and gene expression was determined by western blot analysis. The siRNA used to target PRNP and a scrambled sequence were synthesized by Bioneer (Daejeon, Korea).

Cell viability assay. Subconfluent, exponentially growing MSCs were incubated in a 96-well plate with TUDCA for various times. Cell viability were determined using a modified 3-(4,5-dimethylthiazol-2-yl)-2,5diphenyltetrazolium bromide (MTT) assay, which is based on the conversion of tetrazolium salt 3-(4,5-dime thylthiazol-2-yl)-5-(3-carboxymethoxyphenyl)-2-(4-sulfophenyl)-2-tetrazolium to formazan by mitochondrial $\mathrm{NAD}(\mathrm{P}) \mathrm{H}$-dependent oxidoreductase enzymes. Formazan levels were quantified by measuring the absorbance at $575 \mathrm{~nm}$ using a microplate reader (Tecan, Männedorf, Switzerland).

PI/Annexin V flow cytometric analysis. Apoptosis of MSCs was assessed with a Cyflow Cube 8 (Partec, Münster, Germany) after staining the cells with Annexin V-FITC and propidium iodide (PI) (De Novo Software, Los Angeles, CA). Data analysis was performed using standard FSC Express (De Novo Software, Los Angeles, CA).

Catalase activity. Prior to enzyme activity measure, cells were plated in $100-\mathrm{mm}$ tissue culture plates and grown to 70-75\% confluence. Cells were washed twice in PBS and then collected and resuspended lysis buffer ( $1 \%$ Triton X-100 in $50 \mathrm{mM}$ Tris- $\mathrm{HCl}$ [pH 7.4] containing $150 \mathrm{mM} \mathrm{NaCl}, 5 \mathrm{mM}$ EDTA, $2 \mathrm{mM} \mathrm{Na}_{3} \mathrm{VO}_{4}, 2.5 \mathrm{mM}$ $\mathrm{Na}_{4} \mathrm{PO}_{7}, 100 \mathrm{mM} \mathrm{NaF}$, and protease inhibitors). Sample were incubated for $30 \mathrm{~min}$ on ice and centrifuged at $14000 \mathrm{rpm}$ for $30 \mathrm{~min}$ at $4^{\circ} \mathrm{C}$. Collecting supernatant fraction was measured for protein concentrations using the Micro BCA assay (Thermo Fisher Scientific). Enzyme activity was measured as the decrease in $\mathrm{H}_{2} \mathrm{O}_{2}(200 \mathrm{mM})$ 
absorbance at $240 \mathrm{~nm}$. The Catalase Assay Kit (Sigma-Aldrich) was used to measure the activity in milli unts of enzymatic activity per $\mathrm{mg}$ of protein contained in the samples ( $\mathrm{mU} / \mathrm{mg}$ protein).

Statistical analysis. Results are expressed as the mean \pm standard error of the mean (SEM). All of the experiments were analyzed by one-way analysis of variance (ANOVA). Some comparisons of $\geq 3$ groups were made using the Bonferroni-Dunn test. A P value $<0.05$ was considered statistically significant.

\section{References}

1. Wang, Y., Chen, X., Cao, W. \& Shi, Y. Plasticity of mesenchymal stem cells in immunomodulation: pathological and therapeutic implications. Nature immunology 15, 1009-1016, doi: 10.1038/ni.3002 (2014).

2. Amiri, F., Jahanian-Najafabadi, A. \& Roudkenar, M. H. In vitro augmentation of mesenchymal stem cells viability in stressful microenvironments: In vitro augmentation of mesenchymal stem cells viability. Cell stress \& chaperones 20, 237-251, doi: 10.1007/ s12192-014-0560-1 (2015).

3. Tabas, I. \& Ron, D. Integrating the mechanisms of apoptosis induced by endoplasmic reticulum stress. Nature cell biology 13, 184-190, doi: 10.1038/ncb0311-184 (2011).

4. Walter, P. \& Ron, D. The unfolded protein response: from stress pathway to homeostatic regulation. Science 334, 1081-1086, doi: 10.1126/science.1209038 (2011).

5. Prusiner, S. B. Novel proteinaceous infectious particles cause scrapie. Science 216, 136-144 (1982).

6. Legname, G. et al. Synthetic mammalian prions. Science 305, 673-676, doi: 10.1126/science.1100195 (2004).

7. Steele, A. D., Emsley, J. G., Ozdinler, P. H., Lindquist, S. \& Macklis, J. D. Prion protein (PrPc) positively regulates neural precursor proliferation during developmental and adult mammalian neurogenesis. Proceedings of the National Academy of Sciences of the United States of America 103, 3416-3421, doi: 10.1073/pnas.0511290103 (2006).

8. Doeppner, T. R. et al. Cellular prion protein promotes post-ischemic neuronal survival, angioneurogenesis and enhances neural progenitor cell homing via proteasome inhibition. Cell death \& disease 6, e2024, doi: 10.1038/cddis.2015.365 (2015).

9. Aguzzi, A. \& Polymenidou, M. Mammalian prion biology: one century of evolving concepts. Cell 116, 313-327 (2004).

10. Zhang, C. C., Steele, A. D., Lindquist, S. \& Lodish, H. F. Prion protein is expressed on long-term repopulating hematopoietic stem cells and is important for their self-renewal. Proceedings of the National Academy of Sciences of the United States of America 103, 2184-2189, doi: 10.1073/pnas.0510577103 (2006).

11. Lindor, K. D. et al. Primary biliary cirrhosis. Hepatology 50, 291-308, doi: 10.1002/hep.22906 (2009).

12. Castro-Caldas, M. et al. Tauroursodeoxycholic acid prevents MPTP-induced dopaminergic cell death in a mouse model of Parkinson's disease. Molecular neurobiology 46, 475-486, doi: 10.1007/s12035-012-8295-4 (2012).

13. Liu, C., Cao, Y., Yang, X., Shan, P. \& Liu, H. Tauroursodeoxycholic acid suppresses endoplasmic reticulum stress in the chondrocytes of patients with osteoarthritis. International journal of molecular medicine 36, 1081-1087, doi: 10.3892/ijmm.2015.2295 (2015).

14. Cho, J. G. et al. Tauroursodeoxycholic acid, a bile acid, promotes blood vessel repair by recruiting vasculogenic progenitor cells. Stem cells 33, 792-805, doi: 10.1002/stem.1901 (2015).

15. Zhou, Q., Wang, D., Xu, J. \& Chi, B. Effect of Tauroursodeoxycholic Acid and 4-Phenylbutyric Acid on Metabolism of Copper and Zinc in Type 1 Diabetic Mice Model. Biological trace element research 170, 348-356, doi: 10.1007/s12011-015-0474-5 (2016).

16. Cha, B. H. et al. The role of tauroursodeoxycholic acid on adipogenesis of human adipose-derived stem cells by modulation of ER stress. Biomaterials 35, 2851-2858, doi: 10.1016/j.biomaterials.2013.12.067 (2014).

17. Cha, B. H. et al. Administration of tauroursodeoxycholic acid enhances osteogenic differentiation of bone marrow-derived mesenchymal stem cells and bone regeneration. Bone 83, 73-81, doi: 10.1016/j.bone.2015.10.011 (2016).

18. Vang, S., Longley, K., Steer, C. J. \& Low, W. C. The Unexpected Uses of Urso- and Tauroursodeoxycholic Acid in the Treatment of Non-liver Diseases. Global advances in health and medicine: improving healthcare outcomes worldwide 3, 58-69, doi: 10.7453/ gahmj.2014.017 (2014).

19. Xu, C., Bailly-Maitre, B. \& Reed, J. C. Endoplasmic reticulum stress: cell life and death decisions. The Journal of clinical investigation 115, 2656-2664, doi: 10.1172/JCI26373 (2005)

20. Miharada, K., Sigurdsson, V. \& Karlsson, S. Dppa5 improves hematopoietic stem cell activity by reducing endoplasmic reticulum stress. Cell reports 7, 1381-1392, doi: 10.1016/j.celrep.2014.04.056 (2014).

21. Caplan, A. I. \& Correa, D. The MSC: an injury drugstore. Cell stem cell 9, 11-15, doi: 10.1016/j.stem.2011.06.008 (2011).

22. Wu, K. H., Mo, X. M., Han, Z. C. \& Zhou, B. Stem cell engraftment and survival in the ischemic heart. The Annals of thoracic surgery 92, 1917-1925, doi: 10.1016/j.athoracsur.2011.07.012 (2011).

23. Rutkowski, D. T. \& Kaufman, R. J. A trip to the ER: coping with stress. Trends in cell biology 14, 20-28 (2004).

24. Kim, R., Emi, M., Tanabe, K. \& Murakami, S. Role of the unfolded protein response in cell death. Apoptosis: an international journal on programmed cell death 11, 5-13, doi: 10.1007/s10495-005-3088-0 (2006).

25. Bertolotti, A., Zhang, Y., Hendershot, L. M., Harding, H. P. \& Ron, D. Dynamic interaction of BiP and ER stress transducers in the unfolded-protein response. Nature cell biology 2, 326-332, doi: 10.1038/35014014 (2000).

26. Chen, Y. \& Brandizzi, F. IRE1: ER stress sensor and cell fate executor. Trends in cell biology 23, 547-555, doi: 10.1016/j. tcb.2013.06.005 (2013).

27. Hetz, C. The unfolded protein response: controlling cell fate decisions under ER stress and beyond. Nature reviews. Molecular cell biology 13, 89-102, doi: 10.1038/nrm3270 (2012).

28. Hung, J. H. et al. Endoplasmic reticulum stress stimulates the expression of cyclooxygenase- 2 through activation of NF-kappaB and pp38 mitogen-activated protein kinase. The Journal of biological chemistry 279, 46384-46392, doi: 10.1074/jbc.M403568200 (2004).

29. Marciniak, S. J. et al. CHOP induces death by promoting protein synthesis and oxidation in the stressed endoplasmic reticulum. Genes \& development 18, 3066-3077, doi: 10.1101/gad.1250704 (2004).

30. McLennan, N. F. et al. Prion protein accumulation and neuroprotection in hypoxic brain damage. The American journal of pathology 165, 227-235, doi: 10.1016/S0002-9440(10)63291-9 (2004).

31. Roucou, X., Gains, M. \& LeBlanc, A. C. Neuroprotective functions of prion protein. Journal of neuroscience research 75, 153-161, doi: 10.1002/jnr.10864 (2004)

32. Onodera, T., Sakudo, A., Tsubone, H. \& Itohara, S. Review of studies that have used knockout mice to assess normal function of prion protein under immunological or pathophysiological stress. Microbiology and immunology 58, 361-374, doi: 10.1111/13480421.12162 (2014).

33. Shyu, W. C. et al. Overexpression of PrPC by adenovirus-mediated gene targeting reduces ischemic injury in a stroke rat model. The Journal of neuroscience: the official journal of the Society for Neuroscience 25, 8967-8977, doi: 10.1523/JNEUROSCI.1115-05.2005 (2005).

34. Brown, D. R., Nicholas, R. S. \& Canevari, L. Lack of prion protein expression results in a neuronal phenotype sensitive to stress. Journal of neuroscience research 67, 211-224 (2002).

35. Spudich, A. et al. Aggravation of ischemic brain injury by prion protein deficiency: role of ERK-1/-2 and STAT-1. Neurobiology of disease 20, 442-449, doi: 10.1016/j.nbd.2005.04.002 (2005). 
36. Weise, J. et al. Deletion of cellular prion protein results in reduced Akt activation, enhanced postischemic caspase-3 activation, and exacerbation of ischemic brain injury. Stroke; a journal of cerebral circulation 37, 1296-1300, doi: 10.1161/01.STR.0000217262.03192. d4 (2006).

37. Han, Y. S. et al. Fucoidan protects mesenchymal stem cells against oxidative stress and enhances vascular regeneration in a murine hindlimb ischemia model. International journal of cardiology 198, 187-195, doi: 10.1016/j.ijcard.2015.06.070 (2015).

38. Manning, B. D. \& Cantley, L. C. AKT/PKB signaling: navigating downstream. Cell 129, 1261-1274, doi: 10.1016/j.cell.2007.06.009 (2007).

39. Salvado, L., Palomer, X., Barroso, E. \& Vazquez-Carrera, M. Targeting endoplasmic reticulum stress in insulin resistance. Trends in endocrinology and metabolism: TEM 26, 438-448, doi: 10.1016/j.tem.2015.05.007 (2015).

40. Zhang, B. et al. Prion Protein Protects against Renal Ischemia/Reperfusion Injury. PloS one 10, e0136923, doi: 10.1371/journal. pone.0136923 (2015).

41. Limbourg, A. et al. Evaluation of postnatal arteriogenesis and angiogenesis in a mouse model of hind-limb ischemia. Nature protocols 4, 1737-1746, doi: 10.1038/nprot.2009.185 (2009).

42. Niiyama, H., Huang, N. F., Rollins, M. D. \& Cooke, J. P. Murine model of hindlimb ischemia. Journal of visualized experiments: JoVE, doi: $10.3791 / 1035$ (2009).

\section{Acknowledgements}

This work was supported by the Soonchunhyang University Research Fund, a National Research Foundation grant funded by the Korean government (NRF-2016R1D1A3B01007727), a grant from the Korean Health Technology R\&D Project, Ministry of Health and Welfare, Re-public of Korea (HI14C2253), and a grant from the Next-Generation Bi-oGreen 21 Program (No. PJ011141), Rural Development Administration, Republic of Korea. The funders had no role in the study design, data collection or analysis, the decision to publish, or preparation of the manuscript.

\section{Author Contributions}

Yeo Min Yoon: conception and design, collection and assembly of data. Jun Hee Lee: conception and design, data analysis and interpretation, manuscript writing. Seung Pil Yun: conception and design, data analysis and interpretation. Yong-Seok Han: collection and assembly of data. Chul Won Yun: collection and assembly of data. Hyun Jik Lee: collection and assembly of data. Sei-Jung Lee: collection and assembly of data. Hyunjin Noh: collection and assembly of data, data analysis and interpretation. Ho Jae Han: conception and design, financial support, data analysis and interpretation, final approval of manuscript. San Hun Lee: conception and design, financial support, collection and assembly of data, data analysis and interpretation, manuscript writing, final approval of manuscript.

\section{Additional Information}

Competing financial interests: The authors declare no competing financial interests.

How to cite this article: Yoon, Y. M. et al. Tauroursodeoxycholic acid reduces ER stress by regulating of Akt-dependent cellular prion protein. Sci. Rep. 6, 39838; doi: 10.1038/srep39838 (2016).

Publisher's note: Springer Nature remains neutral with regard to jurisdictional claims in published maps and institutional affiliations.

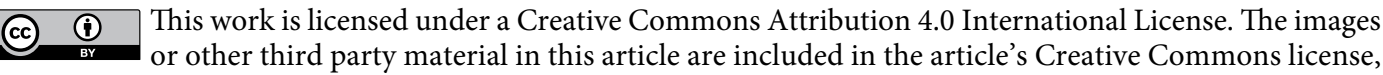
unless indicated otherwise in the credit line; if the material is not included under the Creative Commons license, users will need to obtain permission from the license holder to reproduce the material. To view a copy of this license, visit http://creativecommons.org/licenses/by/4.0/

(c) The Author(s) 2016 